NBER WORKING PAPER SERIES

\title{
CURRENT ACCOUNT ADJUSTMENT: \\ SOME NEW THEORY AND EVIDENCE
}

\author{
Jiandong Ju \\ Shang-Jin Wei \\ Working Paper 13388 \\ http://www.nber.org/papers/w13388
NATIONAL BUREAU OF ECONOMIC RESEARCH
1050 Massachusetts Avenue
Cambridge, MA 02138
September 2007

We thank Rudolfs Bems, Marcel Fratzscher, Caroline Freund, Mick Deveraux, Gordon Hanson, Jean Imbs, Olivier Jeanne, Aart Kraay, Nuno Limao, Jonathan Ostry, David Parsley, Ken Rogoff, Eric van Wincoop and seminar participants at Northwestern University, University of Lausanne, Graduate Institute for International Studies in Geneva, the IMF, and the European Central Bank for helpful discussions and suggestions, and Chang Hong, Erik von Uexkull, and Xuebing Yang for very capable research assistance. The views expressed herein are those of the author(s) and do not necessarily reflect the views of the National Bureau of Economic Research.

(C) 2007 by Jiandong Ju and Shang-Jin Wei. All rights reserved. Short sections of text, not to exceed two paragraphs, may be quoted without explicit permission provided that full credit, including $\odot$ notice, is given to the source. 
Current Account Adjustment: Some New Theory and Evidence

Jiandong Ju and Shang-Jin Wei

NBER Working Paper No. 13388

September 2007

JEL No. E00,F3,F4

\begin{abstract}
This paper aims to provide a theory of current account adjustment that generalizes the textbook version of the intertemporal approach to current account and places domestic labor market institutions at the center stage. In general, in response to a shock, an economy adjusts through a combination of a change in the composition of goods trade (i.e., intra-temporal trade channel) and a change in the current account (i.e., intertemporal trade channel). The more rigid the labor market, the slower the speed of adjustment of the current account towards its long-run equilibrium. Three pieces of evidence are provided that are consistent with the theory.
\end{abstract}

Jiandong $\mathrm{Ju}$

Research Department

International Monetary Fund

70019 th Street NW

Washington, DC 20431

and University of Oklahoma

jju@imf.org

Shang-Jin Wei

Graduate School of Business

Columbia University

Uris Hall, Room 619

3022 Broadway

New York, NY 10027-6902

and NBER

sw2446@columbia.edu 


\section{Contents}

1 Introduction 2

2 An Overlapping-Generations, Multi-Sector Model $\quad 7$

2.1 Production ........................... 9

2.2 The Interest Rate under Trade and Financial Autarky . . . . . . . . 12

2.2.1 Change in Capital Stock $K_{t} \ldots \ldots \ldots \ldots \ldots$

2.2.2 Change in Time Preference $\beta \ldots \ldots \ldots$

2.2.3 Change in Productivity . . . . . . . . . . . . . . . . 13

2.3 A Frictionless Open-Economy . . . . . . . . . . . . . . . . . . . . 13

2.4 Multiple Equilibria . . . . . . . . . . . . . . . . . . . . . . . 15

2.5 Adding Costs to Goods Trade and Capital Flows . . . . . . . . . 16

3 A Model with Labor Market Rigidity 19

3.1 Current Account Adjustment in a Small Country . . . . . . . . . . . 20

3.2 Current Account Adjustment in a Large Country . . . . . . . . . . . 26

4 Some Empirical Evidence $\quad 29$

4.1 Labor Market Rigidity and Trade Structure Flexibility . . . . . . . . 31

4.2 Labor Market Rigidity and Current Account Convergence Speed . . 34

4.2.1 Estimating the Speed of Convergence for Current Account . . 34

4.2.2 Relating the Adjustment Speed of Current Account to Labor Market Rigidity . . . . . . . . . . . . . . . . . 36

4.2.3 Current Account Adjustment Speeds Estimated from a Non-linear TAR Model . . . . . . . . . . . . . . . . . . . 38

4.3 Volatility of Current Account-to-Total Trade Ratio . . . . . . . . . . 39

5 Conclusion $\quad 41$

6 Appendix 45 


\section{Introduction}

One of the major advances in open-economy macroeconomics in the last thirty years is the intertemporal approach to current account, developed in seminal work by Sachs (1981, 1982) and Svesson and Razin (1983), codified in Obstfeld and Rogoff (1996), and now taught to every graduate student in international economics. Relative to the Mundell-Fleming model, the intertemporal approach has a micro-foundation and can be connected to Friedman's permanent income hypothesis. In spite of its appeal at a conceptual level and some partial empirical support, actual current accounts for many countries appear too smooth (i.e., do not seem to move as much as the theory predicts) (see, for example, Roubini, 1988; Sheffrin and Woo, 1990; Otto, 1992; Ghosh, 1995; Ghosh and Ostry, 1995; Obstfeld and Rogoff 1996; and Hussein and de Melo, 1999). The empirical failure of the classic intertemporal approach is sometimes interpreted as a consequence of capital controls. The difficulty with this interpretation is that the empirical failure occurs also with countries that arguably have a very high degree of capital mobility (e.g., the United Kingdom, see Sheffrin and Woo, 1990, and Obstfeld and Rogoff, 1996). In this paper, we propose a theory of current account adjustment that nests the textbook version as a special case. Countries with certain institutional features (to be made clear later) would naturally have relatively smooth current accounts. We also provide some tests that shed light on the theory's predictions.

We argue that the setup of a single tradable-sector in a typical paper on the intertemporal approach is not an innocuous simplification. In particular, in an alternative setup with two tradable sectors to be presented in this paper, any shock that changes a country's capital stock - which can come from an exogenous increase in the domestic capital stock, an increase in the discount factor, or an increase in productivity - could be accommodated by a change in the composition of output and intra-temporal trade with no need for a current account adjustment 
(or intertemporal trade). The intuition behind this apparently major departure from the classic exposition of the intertemporal approach can be understood by appealing to the classic theory of (intra-temporal) trade. In the Heckscher-Ohlin-Samuelson model with two sectors and two factors, factor prices are equalized across countries as long as the goods market is integrated. Even with financial autarky (i.e., no intertemporal trade but with free contemporaneous trade in goods), a shock to the capital stock can be completely accommodated by a change in the composition of output and goods trade. Instead of exporting capital directly (i.e., adjusting the current account), a country can export capital indirectly by exporting more of the capital-intensive product and at the same time importing more of the labor-intensive product (i.e., adjusting the composition of the intra-temporal trade). In this case, going from financial autarky to free international capital mobility need not generate any capital movement. In other words, the intertemporal trade that would have taken place is completely substituted by a change in the composition of goods trade. ${ }^{1}$

Of course, current account does fluctuate in the data; so one cannot stop here. Can we recover the textbook predictions about a current account response to a shock in our model with multiple tradable goods? The answer is yes if we assume that labor is sector-specific. Intuitively, if labor is not mobile across sectors, then domestic output composition cannot change fully in response to a shock to a country's capital stock. So the adjustment must go through the current account. In this case, the current account response would resemble that described in the textbook by Obstfeld and Rogoff (1996). In general, if an economy's labor market is partially flexible, its response to a shock would be a combination of a change in the current account (i.e., the intertemporal trade channel) and a change in the composition of output and goods trade (i.e., the intra-temporal trade channel). The relative importance of the current account channel depends inversely on the degree of domestic labor market

\footnotetext{
${ }^{1}$ The point on potential substitution between international trade and capital mobility is pioneered by Mundell (1957), and discussed by Jones and Neary (1984), Markusen (1983), Markusen and Svensson (1985), Wong (1986), and Neary (1995), among many others.
} 
flexibility.

We note that it is not straightforward to study capital flows (capital account adjustments) in a Heckscher-Ohlin-Samuelson framework: without costs of trade in goods or capital, there are infinite combinations of capital flow and goods trade composition that constitute equilibria. So the exact amount of capital flows is indeterminate. With costs of trade in goods and/or capital, one tends to obtain one of two corner solutions: the adjustment to a shock is either entirely through a change in the goods trade and nothing through capital flows, or only through capital flows with no change in the composition of goods trade. In this paper, we introduce labor market rigidity in addition to costs of trade and capital flows. The costs of trade and capital flows deliver a unique solution, and labor market rigidity effectively generates decreasing returns to scale at the sector level and moves the equilibrium away from the two corners toward an interior solution. This interior solution potentially helps to explain both the "missing trade" puzzle (i.e. the factor content of goods trade is too small relative to the prediction of the Heckscher-Ohlin model, see Trefler, $1995)$ in the trade literature, and the "too smooth current account" puzzle in the open-economy macroeconomics literature.

The model presented in this paper differs in an important way from the more standard generalization of adding a non-tradable sector to the bare-bones intertemporal approach to current account. In models with non-tradable and tradable sectors, frictions in the domestic labor market impede resource reallocation between the non-tradable and tradable sectors. Since, with a single tradable good, one cannot decouple goods trade from current account changes, the more rigid the domestic labor market, the less the current account responds to a shock. This is shown through calibrations by Fernandez de Cordoba and Kehoe (2000) and others. In contrast, since our model allows for a separation between a change in the mix of the goods trade and a change in the current account, it delivers an opposite prediction. A change in the current account and a change in the composition of two tradable 
sectors are substitutes. Therefore, an increase in domestic labor market rigidity that reduces resource reallocation between the two tradable sectors, must increase, rather than reduce, the size of the current account response. Assuming that the distribution of the underlying shocks is the same for all economies, a testable implication of our model is that the variance of the current account is positively associated with the degree of domestic labor market rigidity across countries. We report some empirical evidence that suggests that our channel dominates in the data.

The theory presented in this paper is related to an empirical literature in open-economy macroeconomics that estimates the speed of adjustment of the current account towards the long-run equilibrium (Milesi-Ferretti and Razin, 1998; Freund, 2000; Freund and Warnock, 2005; and Clarida, Goretti, and Taylor, 2005). This line of research typically finds that the current account has a tendency to regress back to its long-run equilibrium, with a speed of adjustment that is heterogenous across countries. The reason behind the mean reversion property and especially the cross-country heterogeneity in the adjustment speed is usually unexplained in the existing studies. Our theory provides a micro-foundation to understand these patterns. In the very short run, every economy can be thought of as being represented by a specific-factor model in which labor does not move between sectors. A shock manifests itself in a change in the economy's current account. In the long run, the economy can be represented by a Heckscher-Ohlin-Samuelson setup in which all factors are perfectly mobile. The same shock is absorbed by a change in the composition of goods production and trade with no change in the current account. The transition from the short run to the long run generates the mean reversion in current account. The time it takes for an economy to move from the very short run to the long run can be assumed to be proportional to its labor market rigidity. If the degree of labor market flexibility is different across countries, so is the convergence speed of current account.

The empirical part of the paper provides three types of results. First, we 
report evidence that an economy's frequency in the adjustment of the goods trade composition is linked to its labor market rigidity. This is a necessary but not sufficient condition for our story. Second, we examine a time-series implication of our theory: current account is mean-reverting, and the adjustment (to its long run equilibrium) is slower in a country with a more rigid labor market. We implement our empirical test in two steps: (a) estimating a speed of current account adjustment country by country; and (b) relating the adjustment speed to labor market rigidity. The result is supportive of our prediction. Third, we report evidence that a country's current account (relative to total trade) is more variable if its labor market is more rigid. We interpret it as suggesting that economies with a more rigid labor market have a larger current account response to the same set of underlying shocks.

The large country case represents an interesting twist. Since one country's current account surplus must be the rest-of-the-world's current account deficit, for a large country, its current account adjustment depends not only on its own labor market institutions, but also on those of the other countries. We show theoretically that, even if a large country has a completely flexible labor market (but the rest of the world does not), part of its response to a shock has to take place through a change in its current account (which is different from the case of a small open economy).

This paper is related to the literature on dynamic Heckscher-Ohlin models pioneered by Oniki and Uzawa (1965), Bardhan (1965), Stiglitz (1970), and Deardorff and Hanson (1978). Other contributions in recent years include Chen (1992), Baxter (1992), Nishimura and Shimomura (2002), Bond, Trask and Wang (2003), and Bajona and Kehoe (2006). Most closely related to our paper is one by Ventura (1997), which studies trade and growth with a model of one final good, two intermediate goods, and labor-augmenting technology. While this literature tends to focus on the question of income convergence across countries, current account adjustment is not typically studied (and a balanced trade is often assumed). Our paper is also related 
to specific factor models in the trade literature. Jones (1971), Mayer (1974), Mussa (1974), and Neary (1978 and 1995) are some of classic papers. The tradition in the trade literature is to assume that capital is sector specific but labor is fully mobile. We choose to focus on rigidity in labor market. Collective bargaining and laws that make it difficult for firms to fire workers could impede labor mobility across sectors. More generally, both labor and capital may be specific in the very short run and become more flexible over time. In our context, frictions in the capital market impede both the access to the international capital market (which reduces the reliance on current account adjustment) and the reallocation of capital between tradable sectors within the economy (which increases the reliance on current account adjustment). Therefore, with these two opposing effects, the linkage between the capital market imperfection and the pattern of current account adjustment is not clear cut. We therefore find it useful to emphasize labor market rigidity.

We organize the rest of the paper in the following way. Section 2 presents an overlapping-generations version of a multi-sector, two-factor, and flexible labor market model. Section 3 introduces labor market rigidity to the model. The labor market institution is parameterized in such a way that the specific-factor model and the Heckscher-Ohlin-Samuelson model are special cases of the formulation. The last part of this section discusses how the large-country case may differ from the small-country case. Section 4 presents some empirical work examining the relationship between domestic labor market institution and patterns of current account adjustment. Finally, Section 5 concludes and points to directions for future research.

\section{An Overlapping-Generations, Multi-Sector Model}

We use an overlapping-generations model to illustrate the idea. After setting up the model, we first discuss how the domestic interest rate under both trade and 
financial autarky would respond to various shocks. The point is to demonstrate that the model behaves in the same way as the textbook version of the intertemporal approach; nothing unusual goes on here. However, when we allow for free trade in goods but retain financial autarky, the model deviates substantially from the textbook predictions. In particular, shocks to the economy are absorbed through changes in the composition of output and goods trade with no change in the domestic interest rate. In this case, moving from financial autarky to financial openness would not generate any current account response to any of these shocks.

We start with a closed-economy case. Each individual is assumed to live for two periods, young and old. $L_{t}$ individuals are born in period $t$. There is no population growth; thus $L_{t}=L_{t-1}=L$. Each individual supplies one unit of labor when she is young, and zero when she is old, and divides the labor income when young between her first period consumption and saving. In the second period, the individual consumes the saving (principle plus interest).

Let $C_{t}^{y}$ and $C_{t}^{o}$ be the consumption in period $t$ of young and old individuals. The utility of an individual born at $t, U_{t}$, is defined as

$$
U_{t}=u\left(C_{t}^{y}\right)+\beta u\left(C_{t+1}^{o}\right), 0<\beta<1
$$

where $\beta$ is time-preference factor.

Let $w_{t}$ be the wage rate per unit of labor at period $t$, and $r_{t+1}$ the interest rate from period $t$ to period $t+1$. The endowment at period $t$ is labor $L_{t}$, and capital stock $K_{t}$ which equals the total saving from the previous period. $L_{t}$ and $K_{t}$ are used to produce two intermediate goods $X_{1 t}$ and $X_{2 t}$, which in turn are used to produce a composite final good $Y_{t}$. The final good is then used for both consumption and investment. We assume that intermediate good $1, X_{1 t}$, is labor intensive, while $X_{2 t}$ is capital intensive. The final good is taken as the numeraire whose price is normalized to 1 . 
The intertemporal budget constraint is

$$
C_{t}^{y}+\frac{C_{t+1}^{o}}{1+r_{t+1}}=w_{t}
$$

The consumer maximizes utility (1) subject to the budget constraint (2). Substituting (2) into (1), the first order condition is:

$$
\frac{\beta u^{\prime}\left(C_{t+1}^{o}\right)}{u^{\prime}\left(C_{t}^{y}\right)}=\frac{1}{1+r_{t+1}}
$$

which is the standard intertemporal Euler equation. (2) and (3) together solve for $C_{t}^{y}$ and $C_{t+1}^{o}$ as functions of $\left(w_{t}, r_{t+1}, \beta\right)$. An individual's saving is $s\left(w_{t}, r_{t+1}, \beta\right)=$ $w_{t}-C_{t}^{y}\left(w_{t}, r_{t+1}, \beta\right)$. Thus, total saving in period $t$ is given by

$$
S_{t}\left(w_{t}, r_{t+1}, \beta, L_{t}\right)=\left[w_{t}-C_{t}^{y}\left(w_{t}, r_{t+1}, \beta\right)\right] L_{t}
$$

In equilibrium $S_{t}$ equals $K_{t+1}$, the capital stock in period $t+1 . C_{t}^{y}\left(w_{t}, r_{t+1}, \beta\right)$ decreases as $r_{t+1}$ increases. Thus $S_{t}\left(w_{t}, r_{t+1}, \beta, L_{t}\right)$ is an increasing function of $r_{t+1}$.

\subsection{Production}

The production setting assumed in this paper is close in spirit to that in Ventura (1997). While international capital flows (or intertemporal trade) are prohibited by assumption in his model, we not only allow for intertemporal trade but make it a central focus of the discussion. The market is perfectly competitive. The production function for the final good is $Y_{t}=G\left(X_{1 t}, X_{2 t}\right)$. The production function for intermediate good $i(=1,2)$ is $X_{i t}=f_{i}\left(A_{t} L_{i t}, K_{i t}\right)$ where $A_{t}$ measures labor productivity, which is exogenous and identical in both sectors. ${ }^{2} H_{i t}=A_{t} L_{i t}$ can be understood as effective labor. All production functions are assumed to be homogeneous of degree one. We assume no depreciation of capital for simplicity.

\footnotetext{
${ }^{2}$ One could introduce the productivity parameter in a different way, e.g., making it Hicks-neutral in the final good, $Y_{t}=A_{t} G\left(X_{1 t}, X_{2 t}\right)$. None of the major results are affected.
} 
The unit cost function for $X_{i t}$ is

$$
\begin{aligned}
\phi_{i}\left(\frac{w_{t}}{A_{t}}, r_{t}\right) & =\min \left\{w_{t} L_{i t}+r_{t} K_{i t} \mid f_{i}\left(A_{t} L_{i t}, K_{i t}\right) \geq 1\right\} \\
& =\min \left\{\left(\frac{w_{t}}{A_{t}}\right) H_{i t}+r_{t} K_{t} \mid f_{i}\left(H_{i t}, K_{i t}\right) \geq 1\right\}
\end{aligned}
$$

We denote $q_{t}=w_{t} / A_{t}$ as the wage rate for one unit of effective labor thereafter.

Free entry ensures zero profit for the intermediate goods producers. We assume that the country's endowment is always within the diversification cone so that both intermediate goods are produced. In period $t+1$ we have:

$$
p_{1, t+1}=\phi_{1}\left(q_{t+1}, r_{t+1}\right) \text { and } p_{2, t+1}=\phi_{2}\left(q_{t+1}, r_{t+1}\right)
$$

where $p_{i}$ is the price of intermediate good $i$. Note that labor and capital are both used to produce intermediate goods. The full employment conditions for labor and capital are, respectively,

$$
\begin{aligned}
a_{1 L t+1} X_{1, t+1}+a_{2 L t+1} X_{2, t+1} & =L_{t+1} \\
a_{1 K t+1} X_{1, t+1}+a_{2 K t+1} X_{2, t+1} & =K_{t+1}
\end{aligned}
$$

where $a_{i L t+1}=\frac{\partial \phi_{i}\left(q_{t+1}, r_{t+1}\right)}{A_{t+1} \partial q_{t+1}}$ and $a_{i K t+1}=\frac{\partial \phi_{i}\left(q_{t+1}, r_{t+1}\right)}{\partial r_{t+1}}$ are labor and capital usages per unit of production at $t+1$, respectively.

The profit maximization for final good producers requires that

$$
p_{1, t+1}=G_{1}^{\prime}\left(X_{1, t+1}, X_{2, t+1}\right) \text { and } p_{2, t+1}=G_{2}^{\prime}\left(X_{1, t+1}, X_{2, t+1}\right)
$$

which implies

$$
\begin{aligned}
G\left(X_{1, t+1}, X_{2, t+1}\right) & =p_{1, t+1} X_{1, t+1}+p_{2, t+1} X_{2, t+1} \\
& =w_{t+1} L_{t+1}+r_{t+1} K_{t+1}
\end{aligned}
$$


Equation (10) is due to homogeneous of degree one of $f($.$) and implies zero profit$ for the final good producers. Equation (11) is due to zero profit for the intermediate goods producers and implies that supply equals demand in the final good market.

Equations (6)- (9) are a system of Heckscher-Ohlin-Samuelson (HOS) framework. For a given vector of product prices $\left(p_{1, t+1}, p_{2, t+1}\right)$, factor prices $\left(q_{t+1}, r_{t+1}\right)$ are determined by (6). Given factor prices, endowment vector $\left(L_{t+1}, K_{t+1}\right)$ then determines the output vector $\left(X_{1, t+1}, X_{2, t+1}\right)$ through equations (7) and (8). Finally, product prices $\left(p_{1, t+1}, p_{2, t+1}\right)$ and sector output are also linked by the market clearing condition (9) for the products. All the key propositions of the HOS model are valid here. In particular, Samuelson's factor price equalization theorem holds: If the product prices $\left(p_{1, t+1}, p_{2, t+1}\right)$ are the same across countries, the effective wage rate, $q_{t+1}$, and the interest rate, $r_{t+1}$, must also be equal across countries.

If $K_{t+1}$ increases, the Rybczynski theorem implies that the capital intensive output $X_{2, t+1}$ increases, while the labor intensive output $X_{1, t+1}$ decreases. Thus the market price of $X_{2, t+1}, p_{2, t+1}$, declines, while $p_{1, t+1}$ increases. Using the Stolper-Samuelson theorem, the return to capital, $r_{t+1}$, declines, while the effective wage rate $q_{t+1}$ increases. Thus, $r\left(L_{t+1}, K_{t+1}\right)$ as a solution to the above system is a decreasing function of $K_{t+1}$. The inverse function of this,

$$
K_{t+1}=I\left(L_{t+1}, r_{t+1}\right)=r^{-1}\left(L_{t+1}, r_{t+1}\right)
$$

defines the investment function. Since the wage rate $w_{t+1}=A_{t+1} q_{t+1}$, an improvement in the (labor-augmenting) productivity increases the wage rate proportionally. However, the interest rate $r_{t+1}$, and the investment function $r^{-1}\left(L_{t+1}, r_{t+1}\right)$ are not affected by a change in the technology $A_{t+1}$. 


\subsection{The Interest Rate under Trade and Financial Autarky}

The equilibrium interest rate in period $t+1, r_{t+1}$, is determined by the saving function (4) (the supply of capital) and the investment function (12) (the demand for capital). This can be represented graphically by a Metzler diagram in Figure 1A that has saving and investment on the horizontal axis and the interest rate on the vertical axis. The upward-sloping $S S$ curve represents the saving function and the downward-sloping II curve represents the investment function. The equilibrium investment $K_{t+1}$ and the interest rate $r_{t+1}$ are determined by the intersection between the $S S$ and $I I$ curves. We consider four cases of comparative statics under autarky (with no goods trade or international capital flows), namely, increases in: (a) the capital stock in period $t,(\mathrm{~b})$ the time preference, (c) the productivity shifter in period $t$ and (d) the productivity shifter in period $t+1$, respectively. The objective is to show that our model under both trade and financial autarky behaves in the same way as the textbook model with one tradable sector. There is nothing unusual so far. This is to be contrasted later with the case of financial openness when our model departs from the textbook model substantially.

\subsubsection{Change in Capital Stock $K_{t}$}

Consider an exogenous increase in the capital stock in period $t$ (possibly due to an infusion of international aid). We apply the standard HOS analysis to equilibrium conditions (6) - (9). The increase in $K_{t}$ results in a reduction in the interest rate $r_{t}$ and an increase in the effective wage rate $q_{t}$. Thus, wage rate in period $t, w_{t}=A_{t} q_{t}$, increases.

Note that individual saving $s\left(w_{t}, r_{t+1}, \beta\right)=w_{t}-C_{t}^{y}\left(w_{t}, r_{t+1}, \beta\right)=\frac{C_{t+1}^{o}\left(w_{t}, r_{t+1}, \beta\right)}{1+r_{t+1}}$. As wage income $w_{t}$ increases, $s\left(w_{t}, r_{t+1}, \beta\right)$ increases. Therefore, in Figure 1a, the saving curve $S S$ shifts out, while the investment curve $I I$ remains unchanged. The equilibrium moves from $E$ to $C$ and $r_{t+1}$ declines. 


\subsubsection{Change in Time Preference $\beta$}

An increase in $\beta$ in period $t$ means that individuals have become more patient and would like to consume less in period $t$ but more in the next period. Thus,

$s\left(w_{t}, r_{t+1}, \beta\right)=\frac{C_{t+1}\left(w_{t}, r_{t+1}, \beta\right)}{1+r_{t+1}}$ increases and the saving curve $S S$ shifts out. Since the demand for capital or the investment curve $I I$ in $t+1$ is not affected, $r_{t+1}$ falls.

\subsubsection{Change in Productivity}

Consider first an increase in $A_{t}$. In response, $w_{t}=A_{t} q_{t}$ must increase proportionally. Thus, the saving curve $S S$ in period $t+1$ shifts out, while the investment curve $I I$ in period $t+1$ is not affected. As a result, $r_{t+1}$ declines.

Consider next an increase in $A_{t+1}$. In our setup, this has no effect on the wage income in period $t$, and therefore no effect on the saving curve $S S$. As we discussed before, in this labor-augmenting setup, an increase in $A_{t+1}$ has no effect on the investment curve $I I$ either. Thus, $r_{t+1}$ does not change.

\subsection{A Frictionless Open-Economy}

Let us now consider the open-economy case in which the world consists of two countries, home and foreign, and allow for both intratemporal and intertemporal trade. Intratemporal trade takes place when a country exports the good of its comparative advantage and imports the good of its comparative disadvantage, whereas intertemporal trade takes place when a country lends capital (or runs a current account surplus) to another country in one period and collects the capital back with interest (or runs a current account deficit) in a future period.

Note that in the textbook exposition of the intertemporal approach, when there is only one tradable sector, only intertemporal trade is feasible (i.e, no intratemporal trade). For comparison, we first discuss how our model would work if intratemporal trade in the intermediate goods is artificially banned. Assume that the two countries are identical to begin with, and then the home country is hit by a shock that increases 
$K_{t}, \beta, A_{t}$ or $A_{t+1}$, respectively. All foreign variables are denoted by a "*". The current account balance is illustrated in Figure 1. As we discussed in the last section, an increase in either $K_{t}, \beta$, or $A_{t}$ would shift the saving curve in period $t+1$ out from $S S$ to $S^{\prime} S^{\prime}$, while the investment curve $I I$ remains unchanged. The post-shock home autarky interest rate, $r_{t+1}^{A \prime}$, is at point $C$ and less than that of abroad at $E^{*}, r_{t+1}^{A *}$. Thus, if only intertemporal trade is allowed, the world interest rate $r$ is above $r_{t+1}^{A \prime}$ but below $r_{t+1}^{A *}$. Home would run a current account surplus in period $t$, and foreign would run a deficit. These results resemble exactly those in Obstfeld and Rogoff (1996). An improvement in the future technology $A_{t+1}$ is only slightly different. In the textbook treatment, this shifts out both the saving curve $S S$ and the investment curve $I I$ so the net effect on the interest rate is ambiguous. In our model, an increase in $A_{t+1}$ has no effect on either the saving curve $S S$ or the investment curve $I I$, and therefore no effect on the interest rate.

Suppose we now allow for free trade in intermediate and final goods, but ban intertemporal trade. We will see that our model's results can be dramatically different from those in Obstfeld and Rogoff (1996). The intratemporal trade in the intermediate and final good equalizes the product prices across countries in every period. That is, $p_{i t}=p_{i t}^{*}$. As equation (6) and the counterpart in foreign country indicate, factor prices $\left(q_{t}, r_{t}\right)$ are determined by the prices of intermediate goods $\left(p_{1 t}, p_{2 t}\right)$ so we must have

$$
q_{t}=q_{t}^{*} \text { and } r_{t}=r_{t}^{*}
$$

in every period $t$. Consider now opening up the economy for international capital flows. With equal interest rates in both countries, there is no incentive for intertemporal trade.

This is basically Samuelson's factor price equalization theorem. The underlying reason for the difference between our setup and that in Obstfeld and Rogoff (1996) 
is that an extra channel for adjustment to shocks - through intratemporal trade in the intermediate goods - has been opened up. In particular, in response to a shock that increases the home country's capital stock, the home country can increase the production and export of the capital intensive intermediate good (i.e., exporting capital indirectly through intratemporal trade), instead of exporting capital directly (i.e., through a current account adjustment).

This idea can be illustrated by the Metzler diagram shown in Figure 1. From the previous section, a shock that augments the home country's capital stock would shift out the home saving curve from $S S$ to $S^{\prime} S^{\prime}$. Let $I^{e} I^{e}$ and $I^{e *} I^{e *}$ be the investment curves at home and abroad under free intratemporal trade, respectively. As Home produces more capital intensive good now than under autarky, and Foreign produces less, the home investment curve $I^{e} I^{e}$ in Figure $1 A$ shifts out, but the foreign investment curve $I^{e *} I^{e *}$ in Figure $1 B$ shifts in. The intratemporal trade moves the domestic equilibrium from $C$ to $G$, and the foreign equilibrium from $E^{*}$ to $G^{*}$. The interest rates after the intratemporal trade are equalized in the two countries.

The following proposition summarizes our discussion:

Proposition 1 In a frictionless world, intratemporal trade in the intermediate goods equalizes interest rates across countries in every period. As a result, there is no incentive for intertemporal trade.

\subsection{Multiple Equilibria}

Going from trade/financial autarky to an open economy, zero intertemporal trade (or zero capital flow) is a possible equilibrium but not the only one. To see this, we use a graphical representation of an integrated world economy from Dixit and Norman (1980) and Helpman and Krugman (1985). In Figure 2, $O$ and $O^{*}$ represent the origins for home and foreign countries, respectively. Vectors $O X_{1}$ and $O X_{2}$ represent the world employment of capital and labor in intermediate Sectors 1 and 2 in the equilibrium of the integrated world economy. Intratemporal trade 
equalizes product and factor prices across two countries. Let $E$ be the distribution of factor endowments without capital flows. That is, $E=\left(L_{t+1}, K_{t+1}\right)$ from origin $O$ and $\left(L_{t+1}^{*}, K_{t+1}^{*}\right)$ from origin $O^{*}$. The full employment conditions in home country, (7) and (8), determine the domestic employment of labor and capital in Sectors 1 and 2, $O A$ and $O B$, respectively. $O^{*} A^{*}$ and $O^{*} B^{*}$ are their foreign-country counterparts. Note that any distribution inside the parallelogram $O X_{1} O^{*} X_{2}$ is a possible equilibrium if both labor and capital are mobile internationally. If labor is not internationally mobile (which we will assume throughout the paper), all points on line $T T^{*}$ are equilibria. For example, point $E^{\prime}$, is one of the feasible equilibria, where home lends $E E^{\prime}$ amount of capital to foreign, and produces $O A^{\prime}$ and $O B^{\prime}$.

Multiple equilibria implies indeterminacy. To achieve a unique equilibrium, we consider first costs of goods trade together with costs of capital flows. This by itself would result in a complete specialization in either intratemporal trade or intertemporal trade. We regard this as unsatisfactory as it is not consistent with the data. Our preferred solution is to relax the assumption of perfect labor mobility within a country in addition to consider costs of trade and capital flows. We will discuss this case in Section 3.

\subsection{Adding Costs to Goods Trade and Capital Flows}

In an influential paper by Obstfeld and Rogoff (2000), trade costs are used to explain the Feldstein-Horioka puzzle, as well as five other major puzzles in international finance. It is argued that "trade costs can create a wedge between the effective real interest rates faced by borrowers and lenders," and "it is precisely such incipient real-interest-rate effects that keep observed current-account imbalances within a modest range." (Obstfeld and Rogoff 2000, pp. 341) In this section, we introduce costs of trade into our multiple-sector model and study the effect of trade costs on current account. As we will see, our results are very different from those of Obstfeld and Rogoff (2000). 
Consider the case in which a shock increases the domestic capital stock at $t+1$ in a world with two otherwise identical countries. That is, $K_{t+1}>K_{t+1}^{*}$. Home is capital abundant, importing the labor-intensive intermediate good 1 and exporting the capital-intensive intermediate good 2. We assume an iceberg transportation cost $\tau$ : for every unit of home (foreign) good shipped abroad, only a fraction $1-\tau$ arrives. Then the no-arbitrage condition implies that

$$
p_{1 t+1}=\frac{p_{1 t+1}^{*}}{1-\tau} \text { and } p_{2 t+1}=(1-\tau) p_{2 t+1}^{*}
$$

For simplicity, we assume a Cobb-Douglas production function for both intermediate goods so that $\phi_{i}\left(q_{t+1}, r_{t+1}\right)=q_{t+1}^{\alpha_{i}} r_{t+1}^{1-\alpha_{i}}$ where $\alpha_{1}>\alpha_{2}$. Rewrite the zero profit conditions for home and foreign countries

$$
\begin{aligned}
p_{1 t+1} & =q_{t+1}^{\alpha_{1}} r_{t+1}^{1-\alpha_{1}} \text { and } p_{2 t+1}=q_{t+1}^{\alpha_{2}} r_{t+1}^{1-\alpha_{2}} \\
(1-\tau) p_{1 t+1} & =q_{t+1}^{* \alpha_{1}} r_{t+1}^{* 1-\alpha_{1}} \text { and } \frac{p_{2 t+1}}{(1-\tau)}=q_{t+1}^{* \alpha_{2}} r_{t+1}^{* 1-\alpha_{2}}
\end{aligned}
$$

which gives

$$
\frac{r_{t+1}}{r_{t+1}^{*}}=(1-\tau)^{\frac{\alpha_{1}+\alpha_{2}}{\alpha_{1}-\alpha_{2}}}
$$

We also assume an iceberg cost of capital flow, $\rho$. Hence, capital flows from home to foreign countries if

$$
\frac{r_{t+1}}{r_{t+1}^{*}}<(1-\rho)
$$

Combining (16) and (17), we conclude that there would be no capital flows (intertemporal trade) if the trade cost is small relative to the cost of capital flows, in the sense that

$$
\tau<1-(1-\rho)^{\frac{\alpha_{1}-\alpha_{2}}{\alpha_{1}+\alpha_{2}}}
$$

In this case, any cross-country interest rate differential would be driven down sufficiently by trade in intermediate goods so that no international capital flows (or intertemporal 
trade) would take place.

On the other hand, if $\tau>1-(1-\rho)^{\frac{\alpha_{1}-\alpha_{2}}{\alpha_{1}+\alpha_{2}}}$, there would be capital flows (from home to foreign country). Note that as long as there exists intratemporal trade, (16) always holds and $r_{t+1}<(1-\rho) r_{t+1}^{*}$. In this case, capital would cross the national border until the capital/labor ratios in the two countries become identical so that intratemporal trade is eliminated. This is essentially Mundell's (1957) argument that intertemporal trade (capital flows) and intratemporal trade are complete substitutes.

The notion of trade costs includes transport cost, tariffs and non-tariff barriers. Costs of capital flows include costs associated with exchange controls, foreign countries' taxes on international investment, and premia for currency and political risks in international financial investment. Given the strong home bias on observes in international financial investment, it is entirely possible that the cost of international capital flows is enormous for many countries. The following proposition summarizes our discussion.

Proposition 2 Introducing costs of trade and costs of capital flow produces a unique equilibrium but at one of the two corners. If the trade cost is small relative to the cost of capital flows in the sense that $\tau<1-(1-\rho)^{\frac{\alpha_{1}-\alpha_{2}}{\alpha_{1}+\alpha_{2}}}$, then the economy's adjustment to shocks takes place entirely through intratemporal trade in intermediate goods (i.e., no current account response). On the other hand, if the trade cost is large relative to the cost of capital flows, then the adjustment to shocks takes place entirely through intertemporal trade (or a current account response).

By construction (with only one tradable sector), Obstfeld and Rogoff (2000) rule out the substitution between intratemporal trade and capital flows. In their model, a higher transportation cost raises incipient real interest differentials and therefore increases the cost of borrowing/lending (i.e., current account adjustment), which reduces the current account imbalance. In contrast, in our model, there would be no incentive for international capital flows if the trade costs were zero, 
since the intratemporal trade in goods would have indirectly realized exports (or imports) of capital. Higher costs of trade would reduce intra-temporal trade and raise intertemporal trade. Thus, our model produces an opposite result from that in Obstfeld and Rogoff with regard to the effect of trade costs on the size of current account. Obstfeld and Rogoff (2000) report a negative empirical correlation between current account surplus and real domestic interest rate and interpret that as supportive evidence for their theory. However, the negative correlation is also consistent with our model except that the direction of causality is reversed.

\section{A Model with Labor Market Rigidity}

We now turn to a model that allows for labor market rigidity. In the framework described in Section 2.5, it is assumed that capital and labor can be costlessly and instantaneously reallocated between sectors within a country. We now relax this assumption. In particular, we introduce some labor market frictions and show that international capital flows and goods trade are no longer complete substitutes. Generally speaking, in response to a shock, an economy's adjustment involves a combination of intratemporal trade (i.e., changes in the composition of goods trade) and intertemporal trade (i.e., borrowing or lending on the international capital market).

The timing of the model is as follows. The economy is in a steady state in period $t$. At the beginning of period $t+1$, young individuals at $t+1$ have made career choices in terms of which sector to work in. $L_{i t+1}$ is hired in sector $i$ at time $t+1$, and the capital stock is $K_{t+1}$. Then a shock (e.g., a change in $K_{t}, \beta$, or $A_{t}$ ) hits the economy. To simplify the analysis, we assume that the cost of goods trade is small relative to the cost of capital flows (in the sense that inequality (18) holds) so that no capital moves across countries in period $t$. Goods trade is assumed to be balanced initially. Since trade in intermediate goods sufficiently narrows the interest 
rate differential between the countries, initially zero capital flow in equilibrium does not imply that the capital/labor ratios are identical in two countries. The home country - to be hit by a shock - is assumed to be capital abundant both before and after the shock. If home is a small country, it is shown that capital will flow from home to foreign countries in period $t$ although the home country exports the capital intensive good at the same time. At the end of this section, we will relax the small country assumption and discuss the large country case.

\subsection{Current Account Adjustment in a Small Country}

Let home be a small country which takes world prices $\left(p_{1 t}, p_{2 t}\right)$ as given. When labor is perfectly mobile across sectors, our model would coincide with the HOS setup discussed in Section 2.5. Domestic factor prices $\left(q_{i, t+1}^{0}, r_{i, t+1}^{0}\right)$ would be determined by (15) both before and after a shock. If labor is assumed to be attached to the sectors, on the other hand, this becomes a specific-factor model. A shock that increases the capital stock would reduce the financial-autarky level of domestic interest rate, but would raise the wage rate. Moreover, the wage rate in the capital-intensive sector $2, w_{2, t+1}^{\prime}$, would be higher than that in the labor intensive sector $1, w_{1, t+1}^{\prime}$. Output in both sectors would increase. In the textbook exposition of classic trade theories, the specific-factor model is viewed as a short-run equilibrium, and the flexible-labor-market HOS model represents the long run equilibrium. In the transition from the short run to the long run, labor (and capital) move from the labor-intensive sector to the capital-intensive sector. Once reaching the long run, factor prices go back to $\left(q_{i, t+1}^{0}, r_{i, t+1}^{0}\right)$, and the capital-intensive output increases, but the labor intensive output decreases, in accordance with the Rybczynski theorem.

Between these two polar cases, there are various levels of partial labor market rigidity. To parameterize the degree of labor market flexibility, we assume that when a unit of labor moves from one sector to another, it would earn only $\lambda$ fraction of the wage in the new sector. $1-\lambda$ fraction of the wage income is lost (due to moving 
costs). A higher $\lambda$ represents a more flexible labor market. At the one extreme, $\lambda=1$ represents the HOS model (in which labor market is completely flexible); at the other extreme, $\lambda=0$ represents the specific-factor model (in which there is no labor mobility). The post-shock wage ratio in the specific-factor model, $\frac{w_{1, t+1}^{\prime}}{w_{2, t+1}^{\prime}}$, defines the upper bound for the wage differential. Therefore, even for $\lambda \leq \frac{w_{1, t+1}^{\prime}}{w_{2, t+1}^{\prime}}$, an individual intending to move from the labor-intensive sector 1 to the capital-intensive sector 2 would see a decline in her wage income. As a result, no labor relocation takes place, and wage rates would stay at $\left(w_{1, t+1}^{\prime}, w_{2, t+1}^{\prime}\right)$. So the entire range of $0 \leq \lambda \leq \frac{w_{1, t+1}^{\prime}}{w_{2, t+1}^{\prime}}$ effectively corresponds to a specific-factor model. If $\lambda>\frac{w_{1, t+1}^{\prime}}{w_{2, t+1}^{\prime}}$, labor in sector 1 would find it worthwhile to move to sector 2 until $w_{1, t+1}=\lambda w_{2, t+1}$. The relationship between the degree of labor market flexibility and the post-shock wage rates in the two sectors can be summarized by the following expression:

$$
w_{1, t+1}=\left\{\begin{array}{l}
\lambda w_{2, t+1}, \frac{w_{1, t+1}^{\prime}}{w_{2, t+1}^{\prime}}<\lambda \leq 1 \\
w_{1, t+1}^{\prime}, \quad 0 \leq \lambda \leq \frac{w_{1, t+1}^{\prime}}{w_{2, t+1}^{\prime}}
\end{array}\right.
$$

Since, when $0 \leq \lambda \leq \frac{w_{1, t+1}^{\prime}}{w_{2, t+1}^{\prime}}$, a (moderate) change in the labor market flexibility has no effect on the economy, we will focus on scenarios in which $\frac{w_{1, t+1}^{\prime}}{w_{2, t+1}^{\prime}}<\lambda \leq 1$ thereafter.

Let $f_{i}\left(A_{t+1} L_{i, t+1}, K_{i, t+1}\right)$ be the production function for intermediate good $i$. We drop the subscript $t+1$ in the rest of this subsection for simplicity. Note that $q_{i}=A w_{i}$, so $w_{1}=\lambda w_{2}$ if and only if $q_{1}=\lambda q_{2}$. The equilibrium conditions become:

$$
\begin{aligned}
p_{1} \frac{\partial f_{1}\left(H_{1}, K_{1}\right)}{\partial K_{1}} & =p_{2} \frac{\partial f_{2}\left(H_{2}, K_{2}\right)}{\partial K_{2}} \\
p_{1} \frac{\partial f_{1}\left(H_{1}, K_{1}\right)}{\partial H_{1}} & =\lambda p_{2} \frac{\partial f_{2}\left(H_{2}, K_{2}\right)}{\partial H_{2}} \\
H_{1}+H_{2} & =A L, \text { and } K_{1}+K_{2}=K^{\prime}
\end{aligned}
$$

Equation (19) states that the marginal products of capital in two sectors are equal, while equation (20) is the condition that $w_{1}=\lambda w_{2}$. 
As discussed by Neary (1978), physical and value factor intensities, $\frac{K_{i}}{L_{i}}$ and $\frac{r K_{i}}{w_{i} L_{i}}$, may differ when $w_{1} \neq w_{2}$, which could generate paradoxical results in comparative statics. To simplify the analysis and avoid these paradoxes, we will assume a Cobb-Douglas production function. Let

$$
f_{1}\left(H_{1}, K_{1}\right)=H_{1}^{\alpha_{1}} K_{1}^{1-\alpha_{1}} \text { and } f_{2}\left(H_{2}, K_{2}\right)=H_{2}^{\alpha_{2}} K_{2}^{1-\alpha_{2}}
$$

where $\alpha_{1}>\alpha_{2}$. Therefore, sector 1 is more labor intensive than sector 2 in both physical and value senses.

We are now ready to discuss the open-economy case. Let the home country be capital abundant after the shock so that the country imports (the labor-intensive) good 1 and exports (the capital-intensive) good 2. Intra-temporal trade in the intermediate goods implies that $p_{1}=\frac{p_{1}^{*}}{1-\tau}$ and $p_{2}=(1-\tau) p_{2}^{*}$. The iceberg cost of capital flows is still denoted by $\rho$. However, the financial-autarky level of the interest rate differential is no longer governed by equation (16). Since labor market rigidity results in decreasing returns to scale at the sector level, intertemporal and intratemporal trade coexists in the equilibrium.

We assume that condition (18) holds in equilibrium before the shock. By assumption, as the domestic interest rate, $r^{0}$, is greater than $(1-\rho) r^{*}$ but less than $r^{*} /(1-\rho)$, there are no capital flows crossing national borders before the shock. Consider a shock that increases the domestic capital stock from $K$ to $K^{\prime}$. We first examine two polar cases of labor market flexibility, and then discuss the more general case of an intermediate level of labor market flexibility.

If $\lambda=1$ (perfectly flexible labor market), with trade openness but financial autarky, factor prices are determined by the zero profit conditions given by (15) and the domestic interest rate stays at $r^{0}$ after the shock. Going from financial autarky to financial openness, there is no incentive for capital to flow out (or in). In other words, all the adjustment to the shock goes through the channel of intratemporal 
trade: the country exports more of the capital-intensive good without any direct capital outflow.

If $\lambda \leq \frac{w_{1 t+1}^{\prime}}{w_{2 t+1}^{\prime}}$ (highly rigid labor market), with trade openness but financial autarky, labor is sector specific and there are decreasing returns to scale at the sector level. The domestic interest rate falls after the shock. If the shock is sufficiently large, the post-shock domestic interest rate, $r^{\prime}$, dips below $(1-\rho) r^{*}$, leading to a capital outflow. It can be easily verified that, without the cost of capital flows, the entire shock to the capital stock, $\Delta K=K^{\prime}-K$, would flow out and would restore the interest rate to the long run level $r^{0}$. Moderately positive costs of capital flows would modify this slightly. Thus, the movement of the current account in this case resembles that of the textbook version of the intertemporal approach.

For intermediate levels of labor market flexibility, $\frac{w_{1}^{\prime}}{w_{2}^{\prime}}<\lambda<1$, the financial-autarky equilibrium is described by equations (19), (20), and (21). For notational convenience, each variable is denoted by a superscript $\lambda$ and the equilibrium is labelled as the $\lambda$-economy. A set of comparative statics, to be used later for our main results, are summarized in the following lemma. A formal proof is relegated to the appendix.

Lemma 1 Suppose that sector 1 is labor intensive in the $\lambda$-economy. Then we have $\frac{\partial H_{1}^{\lambda}}{\partial \lambda}<0, \frac{\partial K_{1}^{\lambda}}{\partial \lambda}<0, \frac{\partial r^{\lambda}}{\partial \lambda}>0$, and $\frac{\partial r^{\lambda}}{\partial K}<0$.

When the labor market is partially rigid, some labor moves from sector 1 to sector 2 in response to a shock, with an associated adjustment of capital between the two sectors as well. The amounts of labor used in two sectors, $H_{1}^{\lambda}<H_{1}$ and $H_{2}^{\lambda}>H_{2}$, are determined by the wage rate equation (20). The interest rate is now between the two polar cases, $r^{\prime}<r^{\lambda}<r^{0}$. The more flexible the labor market, the closer the interest rate to $r^{0}$. If the shock is sufficiently large, the financial-autarky level of interest rate becomes $r^{\lambda}<(1-\rho) r^{*}$, resulting in a capital outflow under financial openness. As capital flows out, $r^{\lambda}$ increases, while the wage rate differential $w_{2}^{\lambda}-w_{1}^{\lambda}$ shrinks so that $w_{1}^{\lambda} / w_{2}^{\lambda}>\lambda$. This implies that labor in sector 1 does not 
flow to sector 2 while capital flowing out. Therefore, the $\lambda$-economy is effectively the specific-labor model in which the labor usage in each sector is fixed at $\left(H_{1}^{\lambda}, H_{2}^{\lambda}\right)$, respectively. As we again have decreasing returns to scale, capital will flow out until the domestic interest rate reaches $(1-\rho) r^{*}$. Since $r^{\lambda}>r^{\prime}$ under financial autarky, only a part of $\Delta K=K^{\prime}-K$ flows out under financial openness. In other words, a change in the current account is only a part of the adjustment in response to the shock; the remaining adjustment must go through a change in the composition of goods trade.

More formally, let $B=K^{\prime}-K^{\prime \prime}$ denote the amount of capital outflow. When $\frac{w_{1}^{\prime}}{w_{2}^{\prime}}<\lambda<1$, the interest rate is determined by the labor market flexibility parameter $\lambda$, and the capital stock employed in the home country $K^{\prime \prime}$. That is, $r^{\lambda}=r^{\lambda}\left(\lambda, K^{\prime \prime}\right)=$ $r\left(\lambda, K^{\prime}-B\right)$. Thus, the amount of capital outflow is determined by

$$
r^{\lambda}\left(\lambda, K^{\prime}-B\right)=(1-\rho) r^{*}
$$

Differentiating equation (23), we obtain the result that the size of the current account response to a given shock is inversely related to labor market flexibility:

$$
\frac{d B}{d \lambda}=\frac{\frac{\partial r^{\lambda}(.)}{\partial \lambda}}{\frac{\partial r^{\lambda}(.)}{\partial K}}<0
$$

We summarize our results by the following proposition.

Proposition 3 Consider a small-open economy with labor market flexibility indexed by $\lambda$. When a shock increases the capital stock (by a sufficient size to overcome the cost of capital flows) in the country, it experiences an outflow of capital (i.e., runs a current account surplus). The more flexible the labor market (i.e., the bigger is $\lambda)$, the smaller the current account response.

A graphical illustration in Figure 3 may help us to understand the above analysis. The length of the horizontal axis is equal to the total supply of capital. The 
vertical axis measures the interest rate. The value marginal product of capital curves in sectors 1 and 2, labeled as $V_{1}$ and $V_{2}$, respectively, are plotted relative to origins $O_{1}$ and $O_{2}$. The equilibrium position before a shock is shown by $E^{0}$ where $V_{1}^{0}=p_{1} \partial f_{1}\left(H_{1}^{0}, K_{1}\right) / \partial K_{1}$ and $V_{2}^{0}=p_{2} \partial f_{2}\left(H_{2}^{0}, K-K_{1}\right) / \partial K_{2}$ intersect. A shock that increases the capital stock from $K$ to $K^{\prime}$, shifts origin $O_{2}$ to the right to $O_{2}^{\prime}$ by $\Delta K=K^{\prime}-K$. Correspondingly, $V_{2}^{0}$, is shifted to the right by $\Delta K$ to $V_{2}^{\prime}=p_{2} \partial f_{2}\left(H_{2}^{0}, K^{\prime}-K_{1}\right) / \partial K_{2}$. In the specific-factor model in which labor is not mobile $\left(\lambda \leq \frac{w_{1 t+1}^{\prime}}{w_{2 t+1}^{\prime}}\right)$, the new equilibrium $E^{\prime}$ is determined by the intersection between $V_{1}^{0}$ and $V_{2}^{\prime}$. The interest rate decreases from $r$ to $r^{\prime}$, while capital employed in sector 1, $K_{1}$, increases from $K_{1}^{0}$ to $K_{1}^{1}$. At the constant product prices, the wage rate in each sector must increase, with a greater proportion in the capital intensive sector. In the long-run (which can be thought of as $\lambda=1$ ), factor prices are restored to the long-run equilibrium level, $\left(q^{0}, r^{0}\right)$. Using Rybczynski theorem, the output of the labor intensive sector must fall. That is, both $V_{1}$ and $V_{2}$ shift to the left and intersect at the long-run equilibrium $E^{L}$, which is to the left of point $E^{0}$.

When $\frac{w_{1}^{\prime}}{w_{2}^{\prime}}<\lambda<1$, the equilibrium of the $\lambda$-economy, $E^{\lambda}$, is between the specific-factor equilibrium $E^{\prime}$ and the long run equilibrium $E^{L} \cdot V_{2}^{\prime}$ shifts left to $V_{2}^{\lambda}=p_{2} \partial f_{2}\left(H_{2}^{\lambda}, K^{\prime}-K_{1}\right) / \partial K_{2}$ and $V_{1}^{0}$ shifts left to $V_{1}^{\lambda}=p_{1} \partial f_{1}\left(H_{1}^{\lambda}, K_{1}\right) / \partial K_{1}$ in Figure 3 since $H_{1}^{\lambda}<H_{1}^{0}$ but $H_{2}^{\lambda}=A L-H_{1}^{\lambda}>H_{2}^{0}$. As labor market becomes less rigid, more factors move from sector 1 to sector 2 consequently, and both $V_{2}^{\lambda}$ and $V_{1}^{\lambda}$ will shift to the left further. The interest rate $r^{\lambda}$ increases as $\lambda$ increases so that $r^{\prime}<r^{\lambda}<r^{0}$.

We assume that the shock $\left(\Delta K=K^{\prime}-K\right)$ is sufficiently large so that $r^{\lambda}<$ $(1-\rho) r^{*}$. Therefore, domestic capital will flow out, which shifts both origin $O_{2}^{\prime}$ and $V_{2}^{L}$ to the left in Figure 3. As capital flows out, the home interest rate increases, while wage rate differential shrinks. This implies that labor in each sector sticks to $H_{i}^{\lambda}$ as capital flows. In equilibrium the capital employed by home country is reduced to $K^{\prime \prime}$ and $V_{2}^{\lambda}$ shifts to the left to $V_{2}^{\prime \prime}=p_{2} \partial f_{2}\left(H_{2}^{\lambda}, K^{\prime \prime}-K_{1}\right) / \partial K_{2}$ which intersects 
$V_{1}^{\lambda}$ at $E^{\prime \prime}$; the interest rate is equal to $(1-\rho) r^{*}$.

By similar reasoning, a country runs a current account deficit in response to a shock that temporarily reduces the country's capital stock. Moreover, the size of the current account deficit is inversely related to the degree of domestic labor market flexibility. As the labor market approaches perfect flexibility $(\lambda \rightarrow 1)$, the current account response to a shock approaches zero (since all adjustment takes place instantaneously through a change in the composition of goods trade). This discussion, however, assumes that the country is a price-taker in the world market. We consider next the case of a large country.

\subsection{Current Account Adjustment in a Large Country}

As the capital stock increases from $K$ to $K^{\prime}$ at home, the relative supply of the labor intensive good to the capital intensive good, $X_{1} / X_{2}$, declines. As a result, the world relative price of good $1, p_{1} / p_{2}$, increases. Therefore, in the foreign country, sector 1 expands relative to sector 2 and the wage rate in sector $1, w_{1}^{*}$, is higher than that in sector $2, w_{2}^{*}$. The counterparts of equilibrium conditions (19), (20), and (21) in the foreign country without capital flows are:

$$
\begin{aligned}
p_{1}(1-\tau) \frac{\partial f_{1}\left(H_{1}^{*}, K_{1}^{*}\right)}{\partial K_{1}^{*}} & =\frac{p_{2}}{1-\tau} \frac{\partial f_{2}\left(H_{2}^{*}, K_{2}^{*}\right)}{\partial K_{2}^{*}} \\
\lambda^{*} p_{1}(1-\tau) \frac{\partial f_{1}\left(H_{1}^{*}, K_{1}^{*}\right)}{\partial H_{1}^{*}} & =\frac{p_{2}}{1-\tau} \frac{\partial f_{2}\left(H_{2}^{*}, K_{2}^{*}\right)}{\partial H_{2}^{*}} \\
H_{1}^{*}+H_{2}^{*} & =A^{*} L^{*}, \text { and } K_{1}^{*}+K_{2}^{*}=K^{*}
\end{aligned}
$$

Labor market rigidity in the foreign country, $\lambda^{*}$, differs from that at home. Moreover, cross-sector factor adjustments in the two countries go in opposite directions. Sector 2 expands at home due to the increase in the capital stock, but sector 1 expands in the foreign country due to an increase in the world market relative price of good 1. Equation (26) represents $w_{2}^{*}=\lambda^{*} w_{1}^{*}$ and is the reverse of the equation (20). The 
world market clearing conditions for the intermediate goods are:

$$
\begin{aligned}
& X_{1}\left(p_{1}, p_{2}\right)+X_{1}^{*}\left(p_{1}, p_{2}\right)=f_{1}\left(H_{1}, K_{1}\right)+f_{1}\left(H_{1}^{*}, K_{1}^{*}\right) \\
& X_{2}\left(p_{1}, p_{2}\right)+X_{2}^{*}\left(p_{1}, p_{2}\right)=f_{2}\left(H_{2}, K_{2}\right)+f_{2}\left(H_{2}^{*}, K_{2}^{*}\right)
\end{aligned}
$$

where $X_{i}\left(p_{1}, p_{2}\right)$ is the derived demand for intermediate good $i$ in the home country, which is the inverse function of equation $(9)$, and $X_{i}^{*}\left(p_{1}, p_{2}\right)$ is its counterpart in the foreign country.

First consider intratemporal equilibrium without capital flows. Ten endogenous variables, $H_{1}, K_{1}, H_{2}, K_{2}, H_{1}^{*}, K_{1}^{*}, H_{2}^{*}, K_{2}^{*}, p_{1}$, and $p_{2}$ are determined by ten equations (19), (20), (21), (25), (26), (27), (28), (29). By comparing the domestic interest rate $r$, which is determined by $K_{1} / H_{1}$, with the foreign interest rate $r^{*}$, which is determined by $K_{1}^{*} / H_{1}^{*}$, we can determine the direction of capital flow.

Now let $K^{f}$ be the amount of capital flow (intertemporal trade) between the countries. The equilibrium intratemporal and intertemporal trade is then determined by the ten equations described above, replacing domestic and foreign capital stocks, $K^{\prime}$ and $K^{*}$, by $K^{\prime}-K^{f}$ and $K^{*}+K^{f}$, respectively, and adding a world capital market clearing condition:

$$
p_{1} \frac{\partial f_{1}\left(H_{1}, K_{1}\right)}{\partial K_{1}}=(1-\rho) p_{1}(1-\tau) \frac{\partial f_{1}\left(H_{1}^{*}, K_{1}^{*}\right)}{\partial K_{1}^{*}}
$$

A closed form solution is not possible without some further simplifying assumptions. The comparison between $r$ and $r^{*}$, which depends on the levels of labor market rigidity both at home and abroad, is complicated, too. Fortunately, for one interesting special case we are able to determine the adjustment pattern to a shock. Specifically, if the domestic labor market is perfectly mobile $(\lambda=1)$, but the foreign labor market is rigid $\left(\lambda^{*}<1\right)$, we are able to compare the financial autarky levels of domestic and foreign interest rates and the qualitative results of Proposition 3 remains. 
Using Stolper-Samuelson theorem, the increase in $p_{1} / p_{2}$ reduces the interest rate at home when labor is perfectly mobile. In the foreign country, the increase in $p_{1} / p_{2}$ reallocates factors from the capital intensive sector to the labor intensive sector. As one unit of labor moves from sector 2 to sector 1, more capital would be released in sector 2 than can be absorbed in sector 1 if capital intensities in both sectors were to remain constant. Therefore, as a consequence of the labor adjustment, capital intensities must rise in both sectors. The rigid labor market in the foreign country, however, prevents a required labor adjustment and therefore an increase in capital intensities (a decrease in the interest rate) to the full scale. Therefore, without any cross-country capital movement, the foreign interest rate would be higher than the domestic interest rate. If the shock is sufficiently large, the interest rate differential between two countries would exceed the cost of capital flows. With capital mobility, the home country runs a current account surplus in period $t$.

Intuitively, for a country to avoid using the current account to adjust to a shock, it has to do all the adjustment through a change in the composition of goods trade (exporting more the capital-intensive good and importing more the labor-intensive good). For a large country (e.g., the United States) to be able to do that, the rest of the world would have to do the reverse (adjusting its output mix and composition of goods trade in the opposite direction). Any lack of labor market flexibility in the rest of the world would prevent it from adjusting the output mix and the composition of goods trade fully. As a consequence, the large country with a perfectly flexible labor market would have to adjust to a shock at least partly through its current account if the labor market in the rest of the world is not perfectly flexible. We state the result as follows and relegate a formal proof to the Appendix.

Proposition 4 Consider a two-country world (i.e., both countries are large) in which the labor market is perfectly flexible at home $(\lambda=1)$ but somewhat rigid in the foreign country $\left(\lambda^{*}<1\right)$. When a shock increases the capital stock in the home country, the home country runs a current account surplus in period $t$. 
This proposition suggests that the relationship between labor market flexibility and current account adjustment for a large country is qualitatively different from a small country. For a small country, the more flexible the domestic labor market, the smaller the current account response to a shock. But this feature may not hold for a large country.

\section{Some Empirical Evidence}

In this section, we investigate three questions empirically for small open economies. First, does the flexibility of a country's labor market correspond to the frequency of adjustment in the composition of its goods trade? Second, does labor market rigidity slow down the speed of convergence of an economy's current account to its long-run equilibrium? Third, is a rigid labor market associated with a greater variance of the current account relative to total trade in goods and services?

These three questions are inter-related. In our theory, flexibility of domestic labor market affects an economy's ability to change the composition of goods trade rather than its current account to accommodate a shock. Hence, a necessary condition for our story to work is that flexibility in a country's labor market should be reflected in the flexibility of its trade structure. We note, however, this is not a sufficient condition for our story as other theories could also be consistent with this pattern. ${ }^{3}$

The second question examines an implication of our theory for the dynamics of the current account. While our model does not explicitly study the transition from the short run to the long run, we impute an interpretation about the transition from two comparative statics results in the model. In the very short run, a given economy may be represented by a specific-factor model. According to our theory, the adjustment to a shock takes place entirely through a change in the current account. In the long run, the economy can be represented by a Hescher-Ohlin setup

\footnotetext{
${ }^{3}$ See, for example, Cunat and Melitz (2007).
} 
with a flexible labor market. According to our theory, the effect of the shock is absorbed entirely by a change in the composition of goods trade, and the current account returns to long-run equilibrium level. ${ }^{4}$ Following the theory by Kraay and Ventura (2000), we will not impose the restriction that the current account in the steady state is zero and let it be country specific instead. This reasoning generates the predictions that current account is mean-reverting and that current account adjustment is slower if domestic labor market is less flexible. For the active empirical literature that estimates the mean reversion property of the current account (and finds cross country differences in the speed of current account convergence), our theory can be thought of as a micro-foundation.

The third question we examine is an implication of our theory for the cross-country pattern in the variance of current account (net trade) relative to total trade (exports plus imports). Any economy is subject to various shocks all the time, most of which are not measured and recorded systematically. In the absence of an exhaustive catalogue of all the relevant shocks, we assume that the distribution of the shocks is the same for all economies over a long enough time period. Under this assumption, our theory implies that the more rigid the labor market, the more likely the effects of these shocks show up in the movement in the net trade (current account) rather than the movement in the total trade. In other words, a lower flexibility in the labor market may be associated with a greater variance of current account relative to total trade.

It is tempting to think that any impediment to a reallocation of capital and labor between sectors within an economy would slow down the current account adjustment or increase the variance of the current account relative to the total trade. In other words, our theory may be as much about how capital market rigidities could affect

\footnotetext{
${ }^{4}$ To make it formal, we assume that $e^{-\lambda T}$ denotes the fraction of the wage income that is lost when a unit of labor moves from one sector to another within a time period $T$. In the short run $(T=0)$, the entire wage income would be lost, so no work would wish to move. In the long run $(T=\infty)$, no wage income is lost, so the model becomes the HOS setup. The current paper does not consider an endogenously determined $T$, which is left for future research.
} 
the pattern of current account adjustment. This, however, may not be the case. Consider credit market constraints (an inability to borrow funds quickly from banks or capital market) faced by small and medium-sized firms. Suppose a favorable shock hits an economy that would make it profitable for firms in a particular sector to expand. The inability for these firms to borrow funds quickly due to credit market constraints prevents a quick adjustment in the composition of goods trade. This may lead one to think that the economy would have to turn to the current account to do the adjustment. However, current account adjustment is about borrowing and lending vis a vis the international capital market. If small/medium-sized firms cannot borrow funds quickly at home due to the credit market constraints, it is equally likely that they cannot borrow funds quickly from the international capital market. In this example, imperfections in the credit market impede both the access to the international capital market (i.e., the use of current account to accommodate a shock) and the reallocation of capital between sectors within the economy (i.e., the use of intra-temporal trade to adjust to the shock). Therefore, the linkage between credit market constraints and the pattern of current account adjustment is ambiguous.

\subsection{Labor Market Rigidity and Trade Structure Flexibility}

We first examine whether domestic labor market rigidity affects the churning of trade structure (i.e., the average change in the composition of exports and imports over time). Recent empirical trade studies suggest that working with highly disaggregated sectoral data is important as most of the adjustment in capital-labor ratio likely takes place within a finely defined sector rather than across sectors. For example, Schott (2004) documented that China and France (as examples of developing and developed countries) often appear to export the same set of products to the U.S. (according the US customs' classification of products). However, as their products appear to have different unit values, they are likely to be of different varieties. Since 
China and France have very different capital-to-labor ratios, this suggests that much of the difference in factor content is reflected in different specialization between China and France within a common sector rather than across different sectors. The implication for us is that we need to work with the most disaggregated data possible. Absent a satisfactory way to compute the churning of capital/labor ratio in exports and imports, we compute the degree of churning for exports and imports (for any reason) country by country, using most disaggregated data available on exports and imports from the United Nations' Comtrade database at the HS 6 digit level. ${ }^{5}$

To be precise, Let $s_{X}(j, h, t)=$ the share of product $h$ in country $j$ 's exports in year $t$, and $s_{M}(j, h, t)=$ the share of product $h$ in country $j$ 's imports in year $t$. Then the Trade Structure Churning Index for country $j$, or Churning $(j)$ for short, is defined by

$\operatorname{Churning}(j)=\frac{1}{T} \sum_{t=1}^{T} \sum_{h}\left[\left|s_{X}(j, h, t)-s_{X}(j, h, t-2)\right|+\left|s_{M}(j, h, t)-s_{M}(j, h, t-2)\right|\right]$ where $\mathrm{t}=1996,1998,2000,2002$, and 2004 , and $T=5$. The churning index is bounded between zero (no change in trade structure) and 2 (maximum possible change). The value of the trade structure churning index is reported in Column 3 of Table 1. Since agriculture, dairy farming, and fishery activities (agriculture for short) are generally difficult to switch in and out of, we have also computed a churning index excluding these activities and reported it in Column 4 of Table 1.

The index for labor market rigidities comes from the World Bank Investment Climate Assessment (ICA) based on an enterprise survey conducted by the World Bank in $2003 .^{6}$ Specifically, it is the proportion of managers/survey respondents

\footnotetext{
${ }^{5}$ It would have been useful to also examine churning of the output structure across countries. Unfortunately, the most disaggregated data set on sectoral output, the UNIDO database, has less than 100 sectors. This level of disaggregation is far below that of the trade data we are using here (which has over 5000 sectors at HS 6-digit).

${ }^{6}$ http://iresearch.worldbank.org/InvestmentClimate. The data were used in the World Banks' World Development Report 2005.
} 
in a country who report labor regulation as a major business constraint (out of 18 categories listed on the questionnaire, including quality of infrastructure, macroeconomic instability, tax rate, tax administration, corruption, and crime. Each respondent can report multiple categories as major constraints.) This measure of labor market rigidity is preferable to simply coding the labor market regulations on the book, since the strength of enforcement varies widely across countries. A strong law that is not well enforced is not as binding for firms as a weaker regulation that is strictly enforced. Since survey responses presumably take enforcement into account, the ICA index can be regarded as a de facto measure of labor market rigidity. In any case, the labor market rigidity index is presented in Column 5 of Table 1.

A scatter plot of the trade structure churning index (for all sectors) against the labor market rigidity index is reported in Figure 4. A negative association between the two is evident: countries with a more rigid labor market are more likely to have a low churning of their trade structures. With a t-statistics of -1.75 , the slope coefficient is statistically different from zero at the $10 \%$ level. Brazil is an apparent outlier on the lower right part of the graph. If one removes Brazil, the new slope coefficient is still negative; but with a t-statistics of -1.60 , it is only different from zero at the $15 \%$ level. If we remove agriculture, dairy, and fishery activities from the computation of the trade churning index, the new scatter plot is presented in Figure 5. The negative slope coefficient is more significant (at the $1 \%$ level with a t-statistic at -2.11) than Figure 4. After removing Brazil, the slope coefficient is still negative and significant at the $10 \%$ level (with a t-statistic at -1.94). To summarize, the data suggest that domestic labor market rigidity affects the speed of turnover of an economy's trade structure.

This result is after all not surprising: one would think that impediments to labor reallocation should necessarily slow down the adjustment in the trade structure. In that sense, Figures 4 and 5 can also be read as a confirmation that the measure of labor market rigidity captures useful information about the actual operation of the 
labor markets in these economies.

\subsection{Labor Market Rigidity and Current Account Convergence Speed}

We now turn to the second piece of empirical evidence. One may consider the index of labor market rigidity as representing the length of the time it takes for a given economy to make the transition from the short run to the long run. Our theory then predicts that the speed of convergence of the current account (scaled by GDP) to the long run equilibrium increases with the flexibility of domestic labor market.

Before we present our empirical results, we first make a note of the existing empirical literature in open-economy macroeconomics that examines the mean reversion property or estimates the speed of convergence of the current account towards long-run equilibrium (Milesi Ferretti-Razin, 1988; Freund, 2000; Freund and Warnock, 2005; and Clarida, Goretti, and Taylor, 2005). These estimations are often done for a single or a small number of developed countries and tend to be done without a theoretical microfoundation. Our theory can be regarded as a possible microfoundation for such estimations.

Our own empirical work follows a two-step procedure. In step one, for every country in the sample, we estimate a speed of convergence of current account to GDP ratio towards the steady state. This estimation utilizes the time series information country by country. In step two, we relate the speed of convergence to a country's degree of labor market rigidity. This steps is done for a cross section of countries. We explain the two steps in turn.

\subsubsection{Estimating the Speed of Convergence for Current Account}

Let $x(j, t)$ be the ratio of country $j$ 's ratio of current account to GDP in time $t$, or, $x(j, t)=c a(j, t) / g d p(j, t)$. Using $\Delta$ to denote first difference of a variable, we estimate 


$$
\Delta x(j, t)=\alpha(j)+\beta(j) x(j, t-1)+e(j, t)
$$

for the period 1980-2005. Under the null hypothesis that the current account as a share of GDP does not converge, $\beta(j)=0$. Under the alternative hypothesis that the ratio of current account to GDP converges to a long-run steady state, $\beta(j)$ is negative (and smaller than one in absolute value). The greater is $\beta(j)$ in absolute value, the faster is the speed of convergence. Note that this specification does not impose the constraint that the long-run value of the current account-to-GDP ratio should be zero. The country-specific long-run value in this specification is given by $-\alpha(j) / \beta(j)$. The idea that different countries may have different long-run values is consistent with Kraay and Venture (2000).

Our theory suggests that large economies' current accounts could behave systematically differently from smaller ones as foreign labor market flexibility also affects them. In the empirical tests, we exclude large economies, defined as those whose GDP accounts for more than 5\% of world GDP. Consequently, the United States, Japan and Germany are excluded from the sample.

The estimation is done at both quarterly and annual frequencies. Data on current account and GDP come from the IMF's International Financial Statistics database. Potential serial correlations in the error term is mopped up by higher orders of the lags of the dependent variable (We will later consider a non-linear specification that allows for faster convergence when the current account is sufficiently far away from its long-run equilibrium level). We now turn to the second step of our empirical design, namely, relating the estimated speed of current account convergence to labor market rigidity. 


\subsubsection{Relating the Adjustment Speed of Current Account to Labor Market Rigidity}

Let $R(j)$ be an index of country $j$ 's rigidity of labor market, or a measure of the difficulty in firing or hiring workers. We relate a country's speed of current account adjustment to its labor market rigidity as follows:

$$
\beta(j)=c+\gamma R(j)+u(j)
$$

Under the null hypothesis that current account adjustment is not related to labor market rigidity, $\gamma=0$. Under the alternative hypothesis that a more rigid labor market leads to a slower adjustment in current account, $\gamma>0$ (recall that $\beta(j)$ s are non-positive).

We now turn to the basic results from estimating Equation (32). As a first step, we estimate the speed of current account convergence country by country using quarterly data on the ratio of current account-to-GDP. There are 30 countries for which we simultaneously have quarterly CA data and a measure of labor market rigidity. These regression results are not reported to save space. As a second step, we implement the simplest possible bi-variate linear regression exploring any linkage between a country's speed of current account convergence and its labor market rigidity. The result is reported in Column 1 of Table 2. The slope coefficient is 1.06 and statistically significant. This is consistent with the notion that the current account convergence is systematically slower in countries with more rigid labor markets.

The convergence speed for current account could be affected by factors other than labor market rigidity. Unfortunately, the literature does not provide much guidance on this, and most empirical estimation on current account convergence uses only univariate time series. Since a key benefit of a flexible exchange rate regime is supposed to provide a country with a better insulation from external shocks, one 
might think that exchange rate regime matters for the speed of adjustment. It is well recognized that a country's self-declared (de jure) exchange rate regime does not often describe its actual behavior well (Frankel and Wei, 1994). We therefore add a de facto exchange rate regime classification a la Reinhart and Rogoff (2004). Specifically, a country in a given time period is classified into one of six regimes: a peg to a foreign currency, a crawling peg, a managed float, a float, free falling, and dual exchange rates. Since our regression is a cross-section, we assign an exchange rate regime classification to a country if it spends a majority of the time in that regime during the sample period. The regression result is reported in Column 2 of Table 2. It turns out that the exchange rate regime designations are not statistically significant. The coefficient on labor market rigidity is basically unchanged (with a point estimate of 1.17 and still being statistically significant).

In addition, one might think that the level of economic development (or the quality of public institutions) can affect the speed of adjustment. So we also include per capita GDP (in logarithm) as a control variable. The result is reported in Column 3. It turns out the level of development does not play a significant role in the current account adjustment either.

We have tried other variations: merging various flexible exchange rate regimes into one, using an alternative measure of de facto exchange rate classification a la Levy-Yeyati and Sturzenegger (2003). These results are reported in the last four columns of Table 2. In all these cases, the coefficient on labor market rigidity remains positive and statistically significant at the $10 \%$ level. This suggests that the pattern that a more rigid labor is associated with a slower current account adjustment is robust.

The results so far use quarterly data. However, because annual data on current account/GDP ratio have fewer missing observations than quarterly data, we can work with a larger set of countries. Table 3 reports a set of regressions that relate the current account adjustment parameters estimated using annual data with labor 
market rigidity. The same pattern emerges: a more rigid labor market is associated with a systematically slower speed of current account adjustment. Now, however, the coefficient on per capita GDP is significant as well: the current account adjusts faster in poorer countries on average. The coefficients on the exchange rate regime classifiers are still insignificant, though the negative sign on various flexible regime dummies is consistent with the notion that current account adjusts faster in countries with a flexible exchange rate regime. To check if this result is driven by any outlier, Figure 6 plots the estimates of $\beta(j)$ (speed of current account convergence) against $R(j)$ (labor market rigidity). The figure suggests a robustly positive relationship that is unlikely to be driven by one or two outliers.

\subsubsection{Current Account Adjustment Speeds Estimated from a Non-linear TAR Model}

As Freund and Warnock (2005) and Clarida, Goretti, and Taylor (2005) suggest, the speed of current account adjustment is likely to be non-linear, with faster adjustment for larger initial deviations from the long-run equilibrium. To take this into account, we now estimate the speed of current account adjustment by a threshold autoregressive (or TAR) model.

The TAR model allows the CA/GDP ratio to follow a unit-root process (i.e., no convergence) if its value stays within a certain range but reverts to its long-run equilibrium when the CA/GDP ratio exceeds some threshold values. To be more specific, the CA/GDP ratio in the TAR model is assumed to come from the following data generating process,

$$
\begin{aligned}
\Delta x(j, t) & =\alpha_{1}(j)+\beta(j) x(j, t-1)+e(j, t) & \text { if }|x(j, t-1)|>\phi(j) \\
& =\alpha_{2}(j)+e(j, t) & \text { otherwise }
\end{aligned}
$$


where $\alpha_{1}(j), \alpha_{2}(j), \beta(j)$, and $\phi(j)$ are parameters to be estimated (for every country $j$ in the sample). In practice, the estimation is done in sequence. The value of $\phi(j)$ is determined by a grid search. As O'Connell and Wei (2002) note, if transaction costs or other factors create a zone of non-converging current account, the TAR model provides a more powerful way to detect global stationarity than the linear AR specification - even if the true behavior of CA/GDP does not conform to the TAR specification.

Estimation of these models can be done via maximum likelihood or sequential conditional least squares. Franses and van Dijk (2000) demonstrate the equivalence of the two methods. Procedurally, we estimate the pooled model using the fixed effects panel estimator by performing a grid search over possible values of $\phi$. Starting with an initial value of $\phi$ at 0.003 , the search adds 0.003 in each successive round until $\phi$ reaches the 75 th fractile of the distribution of $x(j, t-1)$.

After we obtain estimates of $\beta(j)$ from a TAR model country by country, we again connect them with the countries' level of labor market rigidity. The results are presented in Tables 4-5 (when the convergence speeds for CA/GDP are estimated with quarterly and annual data, respectively). The coefficients on the measure of labor market rigidity are positive in all specifications and statistically significant at the $10 \%$ level in 13 out of 14 cases. This again confirms the notion that more labor market rigidity is associated with slower convergence for CA/GDP to its long-run equilibrium. In Table 5, there is some evidence that the convergence is faster for countries with a flexible exchange rate regime, or lower level of income.

\subsection{Volatility of Current Account-to-Total Trade Ratio}

Rather than looking at the speed of convergence, another way to gauge a country's reliance on current account to adjust to shocks is to look at the standard deviation of the country's CA/total trade ratio. Under the assumption that the distribution of the underlying shocks is the same across countries, our theory predicts that an 
economy's current account becomes more volatile if its domestic labor market is more rigid. $^{7}$ In this subsection, we compute this standard deviation, country by country, using the time series over the period 1980-2005. We then regress it on the measure of labor market rigidity, plus control variables. To be precise, let $\operatorname{std}(j)=$ standard deviation of $\mathrm{CA} /$ total trade for country $j, R(j)$ be its labor market rigidity, and $Z(j)$ be a vector of other controls, then the specification is:

$$
\operatorname{std}(j)=c+\gamma R(j)+\eta Z(j)+u(j)
$$

The proposition that a country with a more rigid labor market tends to rely more on its current account (relative to total trade) to adjust to shocks is interpreted as implying $\gamma>0$. Since both real and nominal shocks could affect $\mathrm{CA} /$ total trade directly, we include the standard deviation of log CPI and standard deviation of log GDP (scaled by the mean of log GDP) as control variables. In addition, we allow exchange rate regimes to have a direct effect on the variability of the $\mathrm{CA} /$ total trade ratio.

The regression results are presented in the first four columns of Table 6 . The estimates for $\gamma$ are consistently positive and statistically significant at the 10 percent level. The estimates are consistent with the interpretation that labor market rigidity affects a country's relative reliance on its current account to do the adjustment to shocks. The variability of $\log$ CPI is also positively related to the variability of current account (unsurprisingly). A floating exchange rate regime also tends to be associated with more current account variability. Perhaps, surprisingly, GDP variability is not positively associated with current account variability.

A scatter plot of $\operatorname{std}(j)$ against $R(j)$ in Figure 7 suggests that Brazil and Nicaragua may be outliers. We exclude these two countries and re-do the regressions. The results are presented in the last four columns of Table 6 . With this modification

\footnotetext{
${ }^{7}$ Bluedorn (2005) examines, for a set of small island economies in the Caribbean, current account responses to hurricanes. As we do not have measures of labor market rigidity for most of these economies, we do not adopt the idea here.
} 
of the sample, the variability of the current account/GDP ratio is now positively associated with the variability of log GDP (but no longer with log CPI). Most important for us, the positive and statistically significant association between the variability of the $\mathrm{CA} / \mathrm{GDP}$ ratio and labor market rigidity appears to be robust to excluding possible outliers.

Taking together the various pieces of evidence, the data strongly suggest that a country's current account adjustment is closely linked to its labor market flexibility in a way that is consistent with the model in this paper.

\section{Conclusion}

This paper proposes a theory of current account adjustment that places domestic labor market institutions front and center. In particular, an economy's adjustment to a shock generally involves a combination of an intratemporal channel (a change in the composition of goods trade) and an intertemporal channel (a change in net capital flows). When labor is sector specific (which can be regarded as the very short run), all adjustment for a small open economy takes place through capital flows (and the model behaves like the textbook version of an intertemporal approach). When labor is completely mobile within an economy, any shock can be accommodated by a change in the output and trade composition with no change in the current account. A relatively more rigid labor regulation slows down the transition from the short run to the long run, and therefore slows down the speed of convergence for the CA/GDP ratio.

Three pieces of empirical evidence are presented. First, a rigid labor market makes an economy less nimble and more likely to experience a low churning of its trade structure. Second, a higher rigidity of the labor market reduces the speed of convergence of the current account. And third, a country with a rigid labor market is likely to exhibit a higher variance of current account to total trade. These patterns 
are consistent with the theory's predictions.

This paper represents a first attempt to explore how domestic labor market institutions can affect the substitution between intra-temporal trade adjustment and current account adjustment. Many topics in the standard intertemporal approach to current account, such as the role of fiscal policy, non-tradable sector, and asymmetric information, have not been explored in this paper. It would naturally be interesting to rethink each of these topics in our theoretic framework and to re-examine the data if appropriate. We leave these for future research.

\section{References}

[1] Bardhan, P. K. (1965), "Equilibrium Growth in the International Economy," Quarterly Journal of Economics 79: 455-464.

[2] Bajona, Claustre and Timothy J. Kehoe (2006), "Demographics in Dynamic Heckscher-Ohlin Models: Overlapping Generations versus Infinitely Lived Consumers," NBER Working Paper 12566.

[3] Baxter, Marianne (1992), "Fiscal Policy, Specialization, and Trade in the Two-Sector Model: The Return of Ricardo?" Journal of Political Economy 100: $713-744$.

[4] Bluedorn, John (2005), "Hurricanes: Intertemporal Trade and Capital Shocks," Nuffield College Economics Paper 2005-W22.

[5] Bond, Eric W., Kathleen Trask and Ping Wang (2003), "Factor Accumulation and Trade: Dynamic Comparative Advantage with Endogenous Physical and Human Capital," International Economic Review 44: 1041-1060.

[6] Cunat, Alejandro and Marc J. Melitz (2007), "Volatility, Labor Market Flexibility, and the Pattern of Comparative Advantage," CEPR Working Paper 6297.

[7] Chen, Zhiqi (1992), "Long-Run Equilibria in a Dynamic Heckscher-Ohlin Model," Canadian Journal of Economics 25: 923-943.

[8] Clarida, Richard, Manuela Goretti, and Mark P. Taylor (2007), "Are There Thresholds of Current Account Adjustment in the G7?" In G7 Current Account Imbalances: Sustainability and Adjustment, edited by Richard Clarida, The University of Chicago Press, Chapter 5.

[9] Deardorff, Alan and James A. Hanson (1978), "Accumulation and a Long Run Heckscher-Ohlin Theorem," Economic Inquiry 16: 288-292.

[10] Fernandez de Cordoba, G. and Timothy J. Kehoe (2000), "Capital Flows and Real Exchange Rate Fluctuations Following Spain's Entry into the 
European Community," Journal of International Economics, 51 (2000), 49-78.

[11] Franses, Philip Hans, and Dick van Dijk (2000), Nonlinear Time Series Models in Empirical Finance, Cambridge University Press, Cambridge, United Kingdom.

[12] Frankel, Jeffrey, and Shang-Jin Wei (1994), "Yen Bloc or Dollar Bloc? Exchange Rate Policies of the East Asian Economies," in Macroeconomic Linkages: Savings, Exchange Rates, and Capital Flows, edited by Takatoshi Ito and Anne O. Krueger, University of Chicago Press, pp 295-329.

[13] Freund, Caroline (2000), "Current Account Adjustment in Industrialized Countries," Board of Governors of the Federal Reserve System, International Finance Discussion Paper 692.

[14] Freund, Caroline and Francis Warnock (2005), "Current Account Deficits in Industrial Countries: The Bigger They Are, the Harder They Fall?" In G7 Current Account Imbalances: Sustainability and Adjustment, edited by Richard Clarida, The University of Chicago Press.

[15] Ghosh, Atish R. (1995), "International Capital Mobility amongst the Major Industrialised Countries: Too Little or Too Much?" The Economic Journal, 105(428): 107-128.

[16] Ghosh, Atish R. and Jonathan D. Ostry (1995), "The Current Account in Developing Countries: a Perspective from the Consumption Smoothing Approach," World Bank Economic Review 9(2): 305-333.

[17] Ghosh, Atish R. and Jonathan D. Ostry (1997), "Macroeconomic Uncertainty, Precautionary Saving, and the Current Account," Journal of Monetary Economics 40(1): 121-139.

[18] Hussein, Khaled A. and de Mello, Luiz Jr. (1999), "International Capital Mobility in Developing Countries: Theory and Evidence," Journal of International Money and Finance 18: 367-381.

[19] Jones, Ronald W and J. Peter Neary (1984), "The Positive Theory of International Trade," in Handbook of International Economics, V1, edited by R.W. Jones and P.B. Kenen, Amsterdam: North-Holland.

[20] Johnson, David. (1986), "Consumption, Permanent income, and Financial Wealth in Canada: Empirical Evidence on the Intertemporal Approach to the Current Account," Canadian Journal of Economics 19(2): 189-206.

[21] Kraay, Aart, and Jaume Ventura (2000), "Current Accounts in Debtor and Creditor Countries," Quarterly Journal of Economics, November, pp 1137-66.

[22] Levy-Yeyati, Eduardo, and Federico Sturzenegger (2003), "To Float or to Fix: Evidence on the Impact of Exchange Rate Regimes on Growth," American Economic Review, Vol. 93 (4), pp. 1173-1193, 2003. 
[23] Markusen, James R. (1983), "Factor Movements and Commodity Trade as Complements," Journal of International Economics, 19: 341-56.

[24] Markusen, James.R. and L.E.O. Svensson (1985), "Trade in Goods and Factors with International Difference in Technology," International Economic Review, 26: 175-92.

[25] Mayer, Wolfgang (1974), "Short-run and Long-run Equilibrium for a Small Open Economy," Journal of Political Economy 82: 955-67.

[26] Milesi-Ferretti, Gian Maria and Assaf Razin (1998), "Current Account Reversals and Currency Crises: Empirical Regularities," NBER working paper 6620 .

[27] Mundell, Robert A. (1957), "International Trade and Factor Mobility," American Economic Review 47, 321-325.

[28] Mussa, Michael (1974), "Tariffs and the Distribution of Income: the Importance of Factor Specificity, Substituttability, and Intensity in the Short and Long Run," Journal of Political Economy 82: 1191-204.

[29] Neary, J. Peter (1978), "Short-run Capital Specificity and the Pure Theory of International Trade," Economic Journal 88: 488-510.

[30] Neary, J. Peter (1995), "Factor Mobility and International Trade," Canadian Journal of Economics 28: S4-S23.

[31] Nishimura, K. and K. Shimomura (2002), "Trade and Indeterminacy in a Dynamic General Equilibrium Model," Journal of Economic Theory 105: 244-260.

[32] O'Connell, Paul (1998), "Market Frictions and Real Exchange Rates", Journal of International Money and Finance, 17(1), pages 71-95.

[33] O'Connell Paul, and Shang-Jin Wei (2002), "The Bigger They Are, The Harder They Fall: How Price Differences Across U.S. Cities Are Arbitraged", Journal of International Economics, 56(1), pages 21-53.

[34] Obstfeld, Maurice, and Kenneth Rogoff (1996), Foundations of International Macroeconomics, Cambridge, MA: MIT Press.

[35] Obstfeld, Maurice, and Kenneth Rogoff (2000), "The Six Major Puzzles in International Macroeconomics: Is there a Common Cause?" in Ben Bernanke and Kenneth Rogoff (eds.), NBER Macroeconomics Annual 2000, Cambridge: MIT Press, 339-390.

[36] Obstfeld, Maurice and Alan Taylor (1997), "Non-linear Aspects of Goods-Market Arbitrage and Adjustment: Heckscher's Commodity Point Revisited," Journal of Japanese and International Economics, 11, pages 441-479.

[37] Oniki, H. and H. Uzawa (1965), "Patterns of Trade and Investment in a Dynamics Model of International Trade," Review of Economic Studies 32: $15-38$. 
[38] Otto, Glenn (1992), "Testing a Present-Value Model of the Current Account: Evidence from US and Canadian Time Series," Journal of International Money and Finance 11(5): 414-430.

[39] Reinhart, Carmen and Kenneth Rogoff (2004), "A Re-interpretation of Exchange Rate Regimes", Quarterly Journal of Economics.

[40] Roubini, Nouriel (1988), "Current Account and Budget Deficits in an Intertemporal Model of Consumption and Taxation Smoothing: A Solution to the 'Feldstein-Horioka Puzzle'?" NBER Working Paper 2773.

[41] Sachs, Jeffrey (1981), "The Current Account and Macroeconomic Adjustment in the 1970s," Brookings Papers on Economic Activity 1: 201-268.

[42] Sachs, Jeffrey (1982), "The Current Account in the Macroeconomic Adjustment Process," Scandinavian Journal of Economics 84: 147-159.

[43] Sarno, Lucio and Mark Taylor (2004), "Non-Linear Dynamics in Deviations from the Law of One Price: A Broad-Based Empirical Study", Journal of International Money and Finance, 23(1), pages 1-25.

[44] Schott, Peter (2004), "Across-Product versus Within-Product Specialization in International Trade," Quarterly Journal of Economics, 119(2):647-678, May.

[45] Sheffrin, Steven M and Wing Thye Woo (1990), "Present Value Tests of an Intertemporal Model of the Current Account," Journal of International Economics, 29(3-4): 237-253.

[46] Stiglitz, Joseph E. (1970), "Factor Price Equalization in a Dynamic Economy," Journal of Political Economy 78: 456-488.

[47] Svensson, Lars E. O. and Assaf Razin (1983), "The Terms of Trade and the Current Account: the Harberger-Laursen-Metzler Effect," Journal of Political Economy 91: 97-125.

[48] Trefler, Daniel (1995), "The Case of the Missing Trade and Other HOV Mysteries ," American Economic Review 85: 1029-1046.

[49] Ventura, Jaume (1997), "Growth and Interdependence," Quarterly Journal of Economics 112: 57-84.

[50] Wong, Kar-yiu (1986), "Are International Trade and Factor Mobility Substitutes?" Journal of International Economics, 21: 25-44.

\section{Appendix}

In this appendix we prove Lemma 1 and Proposition 4.

\section{Proof of Lemma 1:}

Substituting (21) into (19) and (20) and differentiating these two equations with respect to $\lambda$, we obtain: 


$$
\begin{aligned}
{\left[p_{1} \frac{\partial^{2} f_{1}(.)}{\partial H_{1} \partial K_{1}}+p_{2} \frac{\partial^{2} f_{2}(.)}{\partial H_{2} \partial K_{2}}\right] \frac{\partial H_{1}}{\partial \lambda} } & =-\left[p_{1} \frac{\partial^{2} f_{1}(.)}{\partial K_{1}^{2}}+p_{2} \frac{\partial^{2} f_{2}(.)}{\partial K_{2}^{2}}\right] \frac{\partial K_{1}}{\partial \lambda} \\
{\left[p_{1} \frac{\partial^{2} f_{1}(.)}{\partial H_{1}^{2}}+\lambda p_{2} \frac{\partial^{2} f_{2}(.)}{\partial H_{2}^{2}}\right] \frac{\partial H_{1}}{\partial \lambda} } & =p_{2} \frac{\partial f_{2}(.)}{\partial L_{2}}-\left[p_{1} \frac{\partial^{2} f_{1}(.)}{\partial H_{1} \partial K_{1}}+\lambda p_{2} \frac{\partial^{2} f_{2}(.)}{\partial H_{2} \partial K_{2}}\right] \frac{\partial K_{1}}{\partial \lambda}
\end{aligned}
$$

The homogeneity of degree 1 implies

$$
\begin{aligned}
& H_{i} \frac{\partial^{2} f_{i}(.)}{\partial H_{i} \partial K_{i}}+K_{i} \frac{\partial^{2} f_{i}(.)}{\partial K_{i}^{2}}=0 \\
& H_{i} \frac{\partial^{2} f_{i}(.)}{\partial H_{i}^{2}}+K_{i} \frac{\partial^{2} f_{i}(.)}{\partial H_{i} \partial K_{i}}=0
\end{aligned}
$$

Substituting (37) and (38) into (35) and (36) and solving for $\frac{\partial K_{1}}{\partial \lambda}$, we then have

$$
\frac{\partial K_{1}}{\partial \lambda}\left[\frac{\Phi}{p_{1} \frac{\partial^{2} f_{1}(.)}{\partial H_{1} \partial K_{1}}+p_{2} \frac{\partial^{2} f_{2}(.)}{\partial H_{2} \partial K_{2}}}\right]=p_{2} \frac{\partial f_{2}(.)}{\partial H_{2}}
$$

where

$$
\Phi=-p_{1}^{2} \Delta_{1}-\lambda p_{2}^{2} \Delta_{2}+\Delta_{3}
$$

and

$$
\Delta_{i}=\frac{\partial^{2} f_{i}(.)}{\partial H_{i}^{2}} \frac{\partial^{2} f_{i}(.)}{\partial K_{i}^{2}}-\left(\frac{\partial^{2} f_{i}(.)}{\partial H_{i} \partial K_{i}}\right)^{2}>0 \text { for } i=1,2
$$

since $f_{i}($.$) is concave, and$

$$
\Delta_{3}=p_{1} p_{2} \frac{\partial^{2} f_{1}(.)}{\partial H_{1} \partial K_{1}} \frac{\partial^{2} f_{2}(.)}{\partial H_{2} \partial K_{2}}\left[\frac{K_{2} H_{1}}{H_{2} K_{1}}-1\right]\left[\frac{H_{2} K_{1}}{K_{2} H_{1}}-\lambda\right]
$$

Using (22) to solve for factor demands, we have

$$
\frac{K_{i}}{H_{i}}=\left(\frac{1-\alpha_{i}}{\alpha_{i}}\right)\left(\frac{w_{i}}{r}\right)
$$

$\frac{K_{2}}{H_{2}}>\frac{K_{1}}{H_{1}}$ and $\left(\frac{K_{1}}{H_{1}}\right) /\left(\frac{K_{2}}{H_{2}}\right)<\frac{w_{1}}{w_{2}}=\lambda$ since $\alpha_{1}>\alpha_{2}$ and $w_{1}=\lambda w_{2}$. Thus, $\Delta_{3}<0$, which implies that $\Phi<0$. Using (39), we have $\frac{\partial K_{1}}{\partial \lambda}<0$, and then (35) implies that $\frac{\partial H_{1}}{\partial \lambda}<0$.

We now turn to the sign of $\frac{\partial r}{\partial \lambda}$. Rewrite equations (19) and (20) as

$$
\begin{aligned}
p_{1} \frac{\partial f_{1}\left(1, K_{1} / H_{1}\right)}{\partial K_{1}} & =p_{2} \frac{\partial f_{2}\left(1, K_{2} / H_{2}\right)}{\partial K_{2}} \\
p_{1} \frac{\partial f_{1}\left(1, K_{1} / H_{1}\right)}{\partial H_{1}} & =\lambda p_{2} \frac{\partial f_{2}\left(1, K_{2} / H_{2}\right)}{\partial H_{2}}
\end{aligned}
$$


Differentiating these two equations with respect to $\lambda$ and using (37) and (38), we obtain:

$$
\frac{p_{1} \partial^{2} f_{1}(.)}{\partial K_{1}^{2}}\left[\frac{\lambda K_{2}}{H_{2}}-\frac{K_{1}}{H_{1}}\right] \frac{\partial\left(K_{1} / H_{1}\right)}{\partial \lambda}=p_{2} \frac{\partial f_{2}(.)}{\partial H_{2}}
$$

which implies that $\frac{\partial\left(K_{1} / H_{1}\right)}{\partial \lambda}<0$. Note that $r=p_{1} \frac{\partial f_{1}\left(1, K_{1} / H_{1}\right)}{\partial K_{1}}$. So $\frac{\partial r}{\partial \lambda}>0$.

Finally we prove $\frac{\partial r}{\partial K}<0$. Suppose that labor does not move across two sectors when capital starts to flow out. Differentiating (19) with respect to $K$, we have:

$$
\left(\frac{p_{1} \partial^{2} f_{1}(.)}{\partial K_{1}^{2}}+\frac{p_{2} \partial^{2} f_{2}(.)}{\partial K_{2}^{2}}\right) \frac{\partial K_{1}}{\partial K}=\frac{p_{2} \partial^{2} f_{2}(.)}{\partial K_{2}^{2}}
$$

which implies that $\frac{\partial K_{1}}{\partial K}>0$. As $K$ declines, $K_{1}$ decreases and so that $K_{1} / H_{1}$ decreases since $H_{1}$ does not change when capital starts to flow out. Thus, $r=$ $p_{1} \frac{\partial f_{1}\left(1, K_{1} / H_{1}\right)}{\partial K_{1}}$ increases.

Now differentiating zero profit conditions $p_{1}=\left(w_{1} / A\right)^{\alpha_{1}} r^{1-\alpha_{1}}$ and $p_{2}=\left(w_{2} / A\right)^{\alpha_{2}} r^{1-\alpha_{2}}$, we obtain:

$$
\frac{d\left(w_{1} / w_{2}\right)}{w_{1} / w_{2}}=\left(\frac{\alpha_{1}-\alpha_{2}}{\alpha_{1} \alpha_{2}}\right) \frac{d r}{r}
$$

So $w_{1} / w_{2}$ increases as $r$ increases. Thus $w_{1} / w_{2}>\lambda$ when capital flows out, which implies that labor in sector 1 will not flow to sector 2 . That is, as capital flows out, labor does not move across sectors and $r$ increases, which proves $\frac{\partial r}{\partial K}<0$.

Proof of Proposition 4:

Rewrite equations (25) and (26) as

$$
\begin{aligned}
p_{1}(1-\tau) \frac{\partial f_{1}\left(1, K_{1}^{*} / H_{1}^{*}\right)}{\partial K_{1}^{*}} & =\frac{p_{2}}{1-\tau} \frac{\partial f_{2}\left(1, K_{2}^{*} / H_{2}^{*}\right)}{\partial K_{2}^{*}} \\
\lambda^{*} p_{1}(1-\tau) \frac{\partial f_{1}\left(1, K_{1}^{*} / H_{1}^{*}\right)}{\partial H_{1}^{*}} & =\frac{p_{2}}{1-\tau} \frac{\partial f_{2}\left(1, K_{2}^{*} / H_{2}^{*}\right)}{\partial H_{2}^{*}}
\end{aligned}
$$

Comparing $r=p_{1} \frac{\partial f_{1}\left(1, K_{1} / H_{1}\right)}{\partial K_{1}}$ with $r^{*}=p_{1} \frac{\partial f_{1}\left(1, K_{1}^{*} / H_{1}^{*}\right)}{\partial K_{1}^{*}}$ is equivalent to comparing $K_{1} / H_{1}$ with $K_{1}^{*} / H_{1}^{*}$. Let $\lambda=1$ in (41) and (42). Solving for $K_{i} / H_{i}$, we have $K_{1} / H_{1}=k_{1}\left(p_{1}, p_{2}, 1\right)$. We start from the case that $\tau=0$. Using (43) and (44), we solve for $K_{i}^{*} / H_{i}^{*}$ and have $K_{1}^{*} / H_{1}^{*}=k_{1}\left(p_{1}, p_{2}, \lambda^{*}\right)$. Note that the function forms of $K_{1} / H_{1}$ and $K_{1}^{*} / H_{1}^{*}$ are the same when $\lambda=1$. So we have:

$$
\begin{aligned}
K_{1} / H_{1}-K_{1}^{*} / H_{1}^{*} & =k_{1}\left(p_{1}, p_{2}, 1\right)-k_{1}\left(p_{1}, p_{2}, \lambda^{*}\right) \\
& =\frac{\partial k_{1}\left(p_{1}, p_{2}, \tilde{\lambda}\right)}{\partial \lambda}\left(1-\lambda^{*}\right)
\end{aligned}
$$

where $\lambda^{*}<\tilde{\lambda}<1$. To determine $\frac{\partial k_{1}\left(p_{1}, p_{2}, \tilde{\lambda}\right)}{\partial \lambda}$, we create an artificial small foreign economy which takes world prices as given and has a labor market with rigidity $\widetilde{\lambda}$. Equilibrium conditions in the artificial economy are the same as (43) and (44) but 
replacing $\lambda^{*}$ by $\tilde{\lambda}$. Differentiating equilibrium conditions in the artificial economy with respect to $\tilde{\lambda}$, we obtain:

$$
\frac{p_{1} \partial^{2} f_{1}(.)}{\partial K_{1}^{* 2}}\left[\frac{\widetilde{\lambda} K_{1}^{*}}{H_{1}^{*}}-\frac{K_{2}^{*}}{H_{2}^{*}}\right] \frac{\partial\left(K_{1}^{*} / H_{1}^{*}\right)}{\partial \widetilde{\lambda}}=p_{1} \frac{\partial f_{1}(.)}{\partial H_{1}^{*}}
$$

Using (40) and noting that $w_{2}^{*}=\widetilde{\lambda} w_{1}^{*}$ in the artificial economy, we have $\left(\frac{K_{2}^{*}}{H_{2}^{*}}\right) /\left(\frac{K_{1}^{*}}{H_{1}^{*}}\right)>$ $\frac{w_{2}^{*}}{w_{1}^{*}}=\tilde{\lambda}$. Therefore, $\frac{\partial k_{1}\left(p_{1}, p_{2}, \widetilde{\lambda}\right)}{\partial \lambda}=\frac{\partial\left(K_{1}^{*} / H_{1}^{*}\right)}{\partial \widetilde{\lambda}}>0$. Applying this result to (45), we have $K_{1} / H_{1}>K_{1}^{*} / H_{1}^{*}$. Thus, $r<r^{*}$ at $\tau=0$. Now let $\lambda^{*}$ be constant, but $\tau$ varies. Using similar argument, we can further show that $\left.r^{*}\right|_{\tau>0}>\left.r^{*}\right|_{\tau=0}>r$. As $\tau$ is relatively large, the capital flows from the home country to the foreign country at period $t$, and the larger the value of $\lambda^{*}$, the smaller the amount of capital flow. 

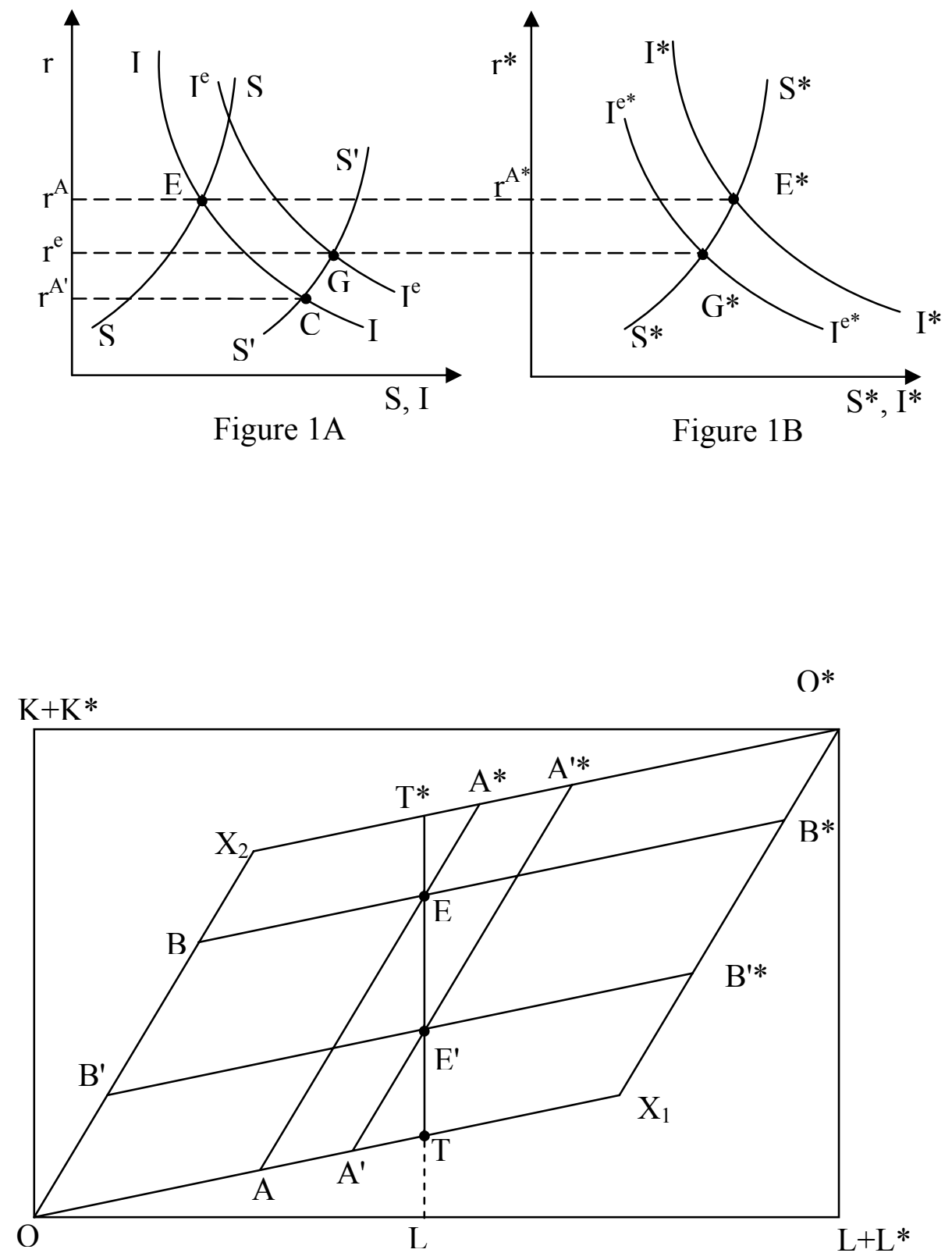

Figure 2 


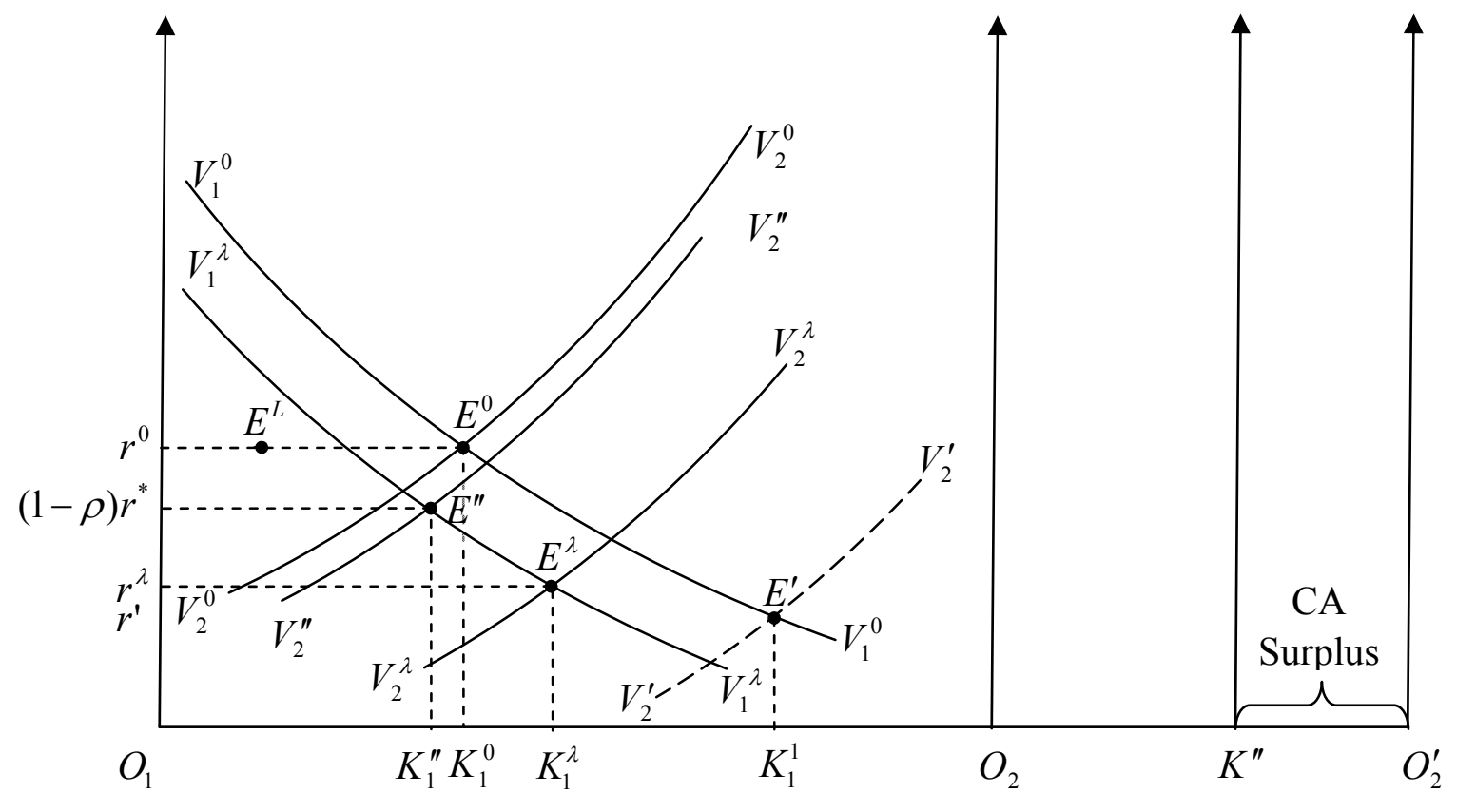

Figure 3 


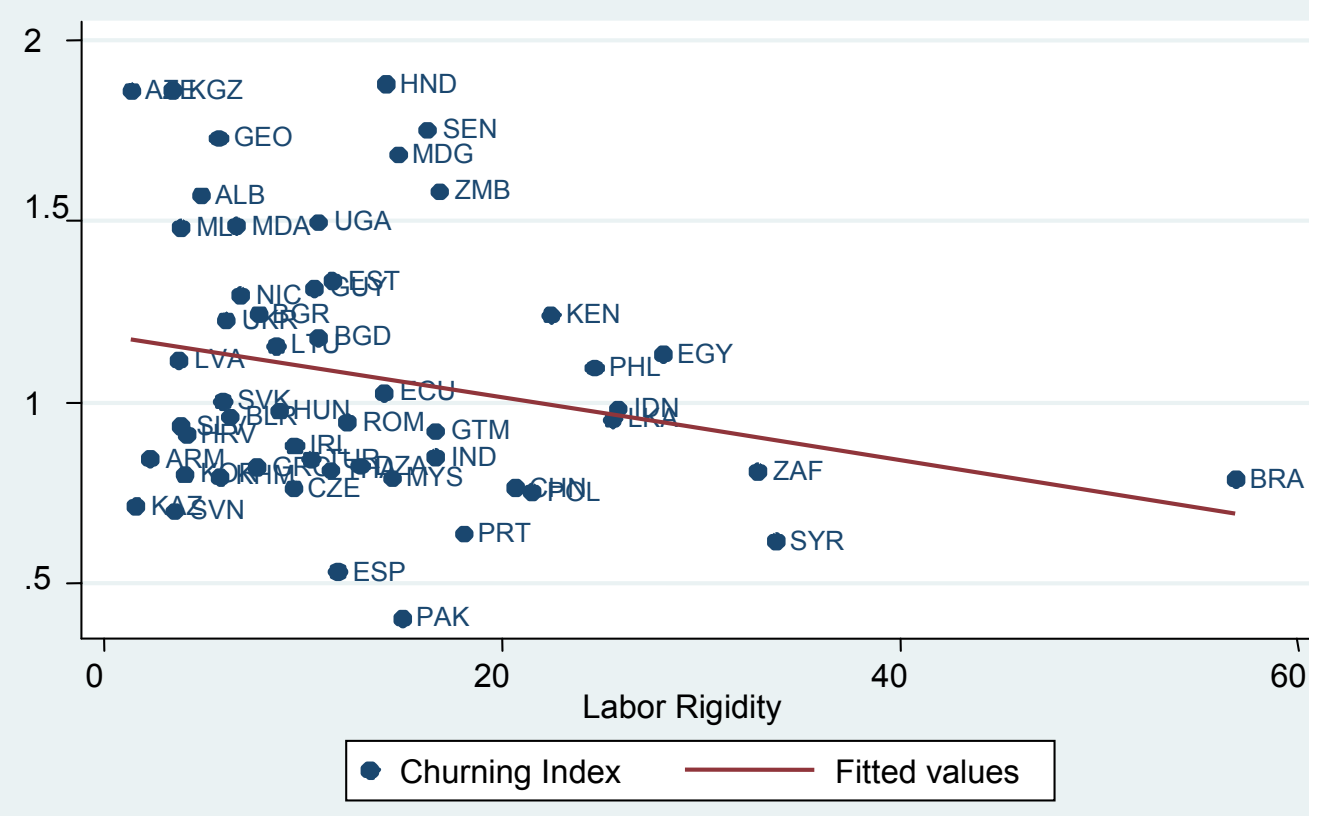

Figure 4: Trade Structure Churning vs Labor Market Rigidity, All Sectors The slope coefficient (standard error) $=-0.009(0.005), \mathrm{t}=-1.75$

Excluding Brazil, the slope coefficient (standard error) $=-0.010(0.006), \mathrm{t}=-1.60$

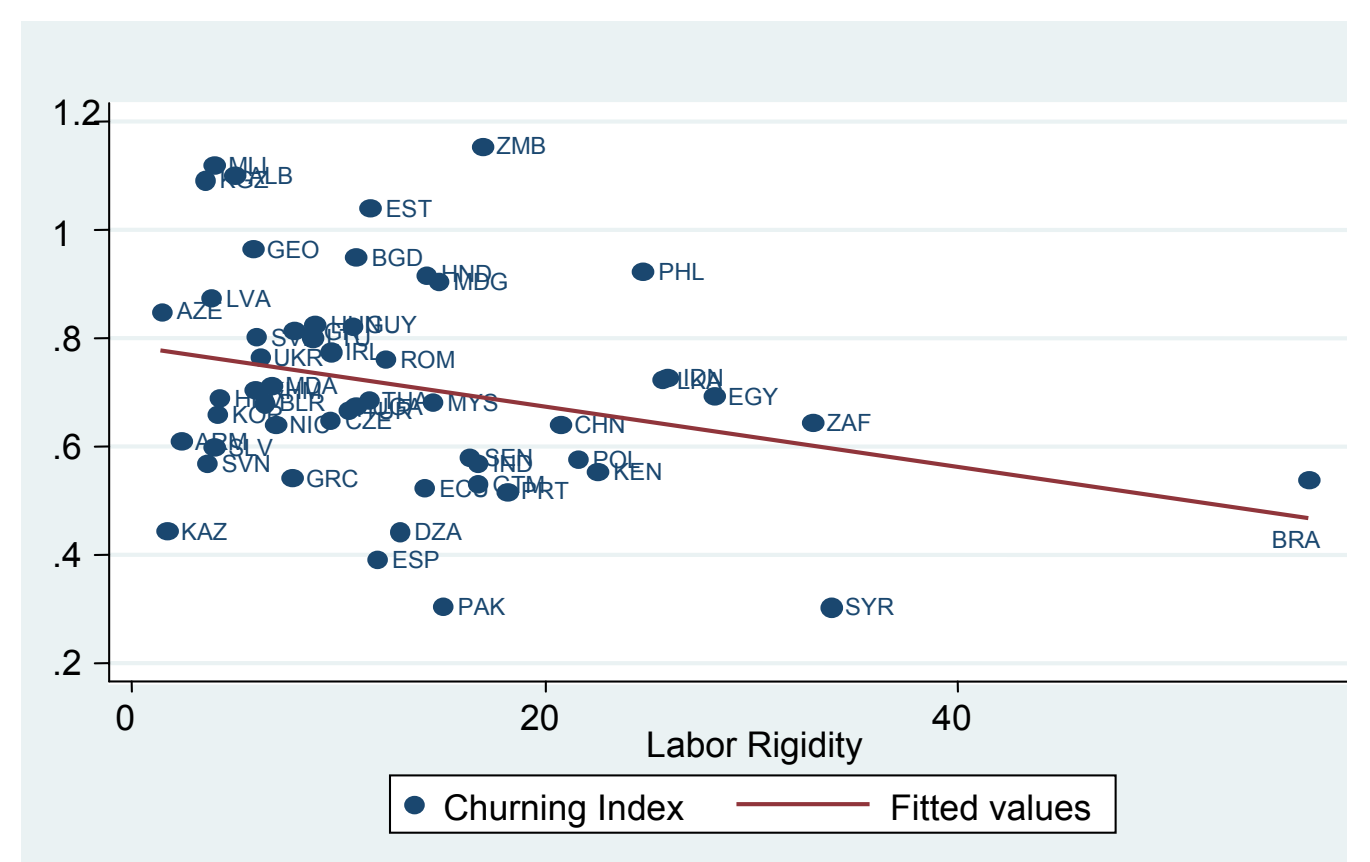

Figure 5: Trade Churning vs Labor Market Rigidity, Excluding Agriculture

The slope coefficient (standard error) $=-0.0056(0.0026), \mathrm{t}=-2.11$

Excluding Brazil, the slope coefficient (standard error) $=-0.0065(0.0034), \mathrm{t}=-1.94$ 


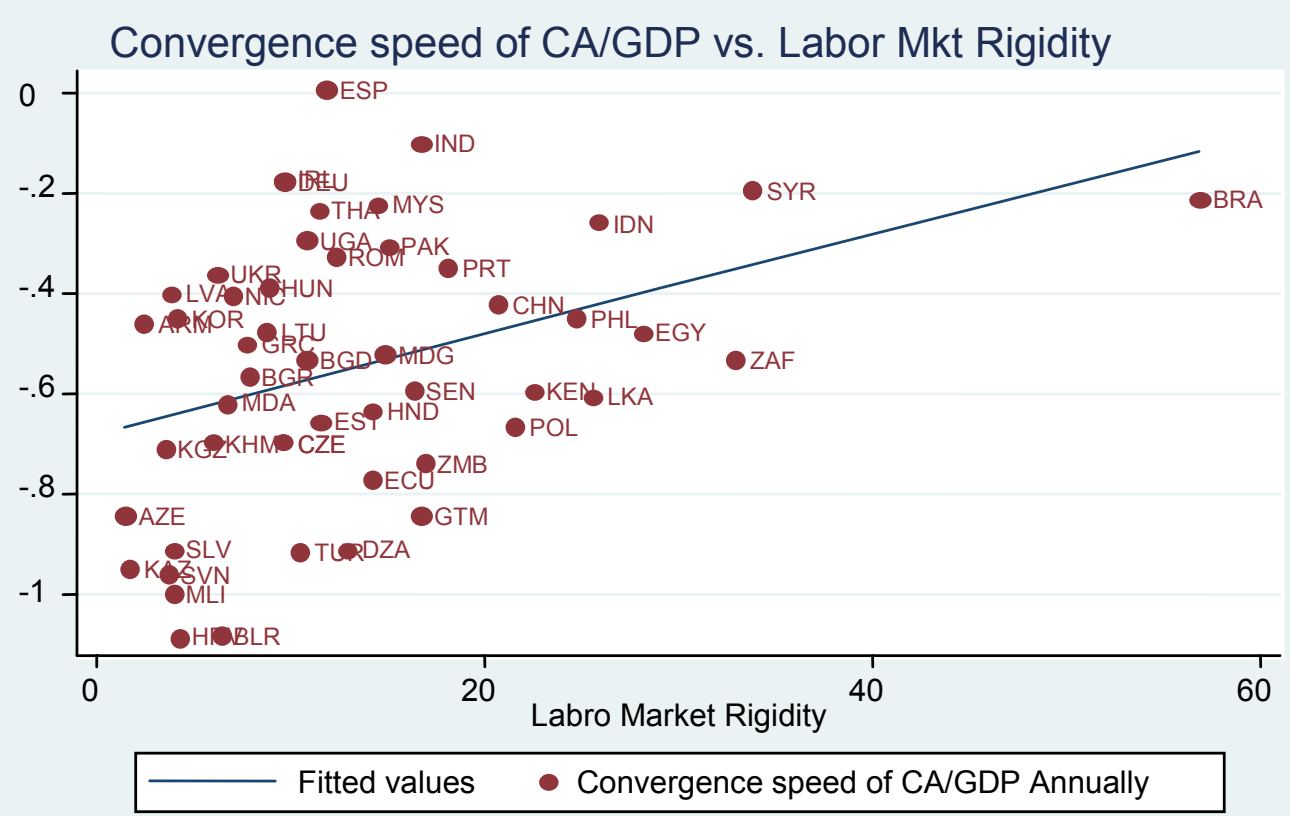

Figure 6: Convergence Speed of CA/GDP vs Labor Market Rigidity

(based on Column 1 of Table 3; Convergence speed estimated with annual data) The slope coefficient (standard error) $=1.012(0.350), \mathrm{t}=2.90$

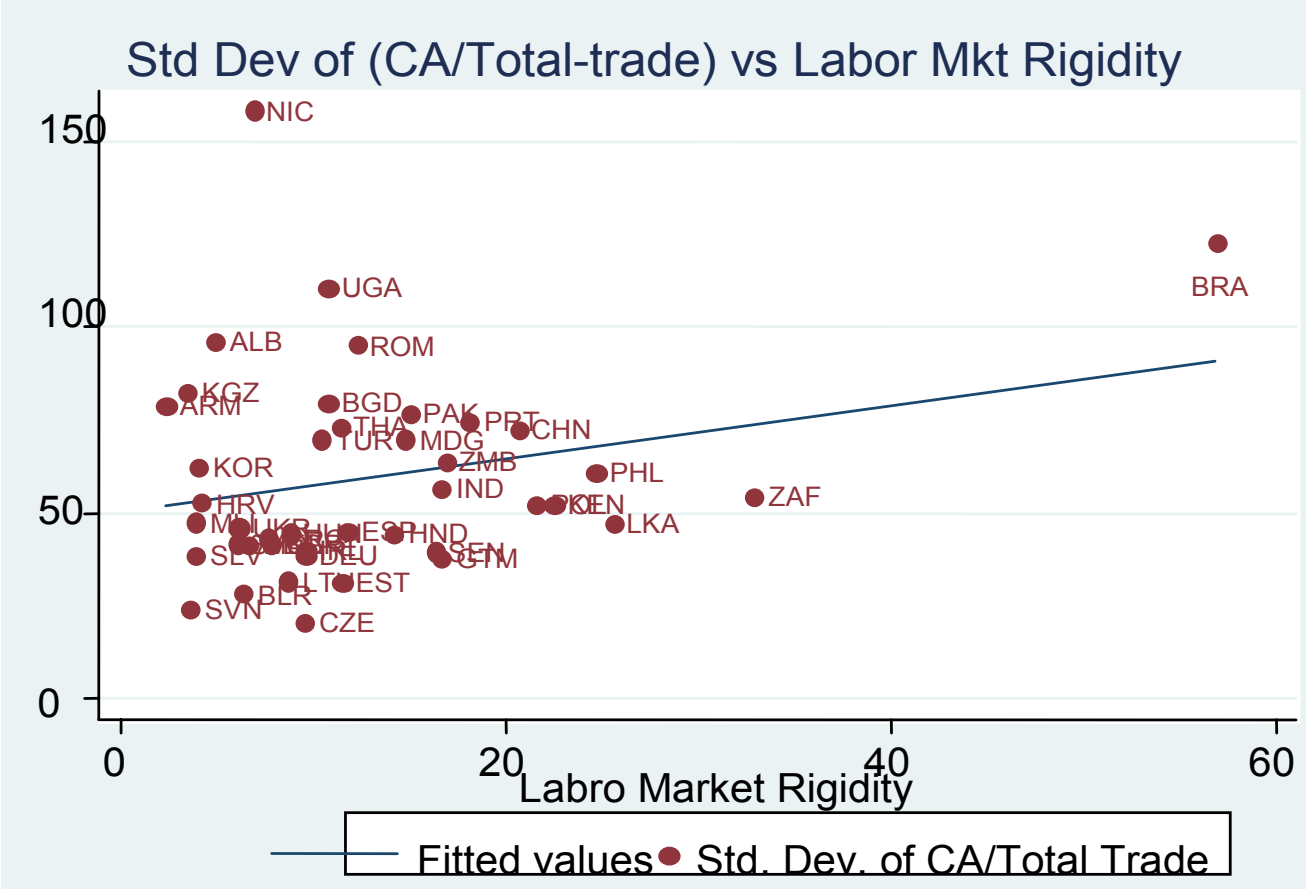

Figure 7: Standard Deviation of (CA/Total Trade) vs Labor Market Rigidity The slope coefficient (standard error) $=13.71(6.51), \mathrm{t}=2.11$ 
Table 1: Labor Market Rigidity and Trade Structure Churning Index

\begin{tabular}{|c|c|c|c|c|}
\hline $\begin{array}{c}\text { Country Code } \\
1\end{array}$ & $\begin{array}{c}\text { Country Name } \\
2\end{array}$ & $\begin{array}{c}\text { Trade Structure } \\
\text { Churning } \\
\text { All sector } \\
\mathbf{3}\end{array}$ & $\begin{array}{c}\text { Trade Structure } \\
\text { Churning Excluding } \\
\text { Agriculture } \\
4\end{array}$ & $\begin{array}{c}\text { Labor Market } \\
\text { Rigidity } \\
5\end{array}$ \\
\hline$\overline{\mathrm{ALB}}$ & Albania & 1.57 & 1.10 & 4.90 \\
\hline ARM & Armenia & 0.84 & 0.61 & 2.35 \\
\hline AZE & Azerbaijan, Rep. of & 1.86 & 0.85 & 1.40 \\
\hline BGD & Bangladesh & 1.18 & 0.95 & 10.80 \\
\hline BGR & Bulgaria & 1.24 & 0.81 & 7.80 \\
\hline BLR & Belarus & 0.96 & 0.68 & 6.35 \\
\hline BRA & Brazil & 0.79 & 0.54 & 56.90 \\
\hline $\mathrm{CHN}$ & China & 0.76 & 0.64 & 20.70 \\
\hline CZE & Czech Republic & 0.76 & 0.65 & 9.55 \\
\hline DZA & Algeria & 0.82 & 0.44 & 12.90 \\
\hline ECU & Ecuador & 1.02 & 0.52 & 14.10 \\
\hline EGY & Egypt & 1.13 & 0.69 & 28.10 \\
\hline ESP & Spain & 0.53 & 0.39 & 11.80 \\
\hline EST & Estonia & 1.33 & 1.04 & 11.50 \\
\hline GEO & Georgia & 1.73 & 0.96 & 5.80 \\
\hline GRC & Greece & 0.82 & 0.54 & 7.70 \\
\hline GTM & Guatemala & 0.92 & 0.53 & 16.70 \\
\hline GUY & Guyana & 1.31 & 0.82 & 10.60 \\
\hline HND & Honduras & 1.88 & 0.92 & 14.20 \\
\hline HRV & Croatia & 0.91 & 0.69 & 4.20 \\
\hline HUN & Hungary & 0.97 & 0.83 & 8.80 \\
\hline IDN & Indonesia & 0.98 & 0.73 & 25.90 \\
\hline IND & India & 0.85 & 0.57 & 16.70 \\
\hline IRL & Ireland & 0.88 & 0.78 & 9.60 \\
\hline KAZ & Kazakhstan & 0.71 & 0.44 & 1.65 \\
\hline KEN & Kenya & 1.24 & 0.55 & 22.50 \\
\hline KGZ & Kyrgyz Republic & 1.86 & 1.09 & 3.50 \\
\hline KHM & Cambodia & 0.79 & 0.71 & 5.90 \\
\hline KOR & Korea & 0.80 & 0.66 & 4.10 \\
\hline LKA & Sri Lanka & 0.95 & 0.72 & 25.60 \\
\hline LTU & Lithuania & 1.15 & 0.80 & 8.70 \\
\hline LVA & Latvia & 1.12 & 0.88 & 3.80 \\
\hline MDA & Moldova & 1.49 & 0.71 & 6.70 \\
\hline MDG & Madagascar & 1.69 & 0.90 & 14.80 \\
\hline MLI & Mali & 1.48 & 1.12 & 3.90 \\
\hline MYS & Malaysia & 0.79 & 0.68 & 14.50 \\
\hline NIC & Nicaragua & 1.29 & 0.64 & 6.90 \\
\hline PAK & Pakistan & 0.40 & 0.30 & 15.00 \\
\hline PHL & Philippines & 1.09 & 0.92 & 24.70 \\
\hline POL & Poland & 0.75 & 0.58 & 21.55 \\
\hline PRT & Portugal & 0.63 & 0.52 & 18.10 \\
\hline
\end{tabular}




\begin{tabular}{llccc} 
ROM & Romania & 0.94 & 0.76 & 12.25 \\
SEN & Senegal & 1.75 & 0.58 & 16.30 \\
SLV & El Salvador & 0.93 & 0.60 & 3.90 \\
SVK & Slovakia & 1.00 & 0.80 & 6.00 \\
SVN & Slovenia & 0.70 & 0.57 & 3.60 \\
SYR & Syrian Arab Republic & 0.61 & 0.30 & 33.80 \\
THA & Thailand & 0.81 & 0.69 & 11.40 \\
TUR & Turkey & 0.84 & 0.67 & 10.45 \\
UGA & Uganda & 1.50 & 0.67 & 10.80 \\
UKR & Ukraine & 1.23 & 0.76 & 6.15 \\
VNM & Vietnam & No data & No data & 10.90 \\
ZAF & South Africa & 0.81 & 0.65 & 32.90 \\
ZMB & Zambia & 1.58 & 1.16 & 16.90 \\
\hline
\end{tabular}

\section{Sources:}

1. Trade Structure Churning Indexes are computed by the authors using most disaggregated data available on exports and imports from the United Nations' Comtrade database at the HS 6 digit level. Let $\mathrm{s}^{\mathrm{X}}(\mathrm{j}, \mathrm{k}, \mathrm{t})=$ share of product $\mathrm{k}$ in country's exports in year $\mathrm{t}$, and $\mathrm{s}^{\mathrm{M}}(\mathrm{j}, \mathrm{k}, \mathrm{t})=$ share of product $\mathrm{k}$ in country j's imports in year $\mathrm{t}$. Then the Trade Structure Churning Index for country $\mathrm{j}$, or Churning(j) for short, is defined by

Churning (j) $=1 / T \sum_{t} \sum_{k}\left[\left|s^{X}(j, k, t)-s^{X}(j, k, t-2)\right|+\left|s^{M}(j, k, t)-s^{M}(j, k, t-2)\right|\right]$

Where $\mathrm{t}=1996,1998,2000,2002$, and 2004, and $\mathrm{T}=5$. The churning index is bounded between zero (no change in trade structure) and 2 (maximum possible change).

Column 3 is computed using data for all HS sectors. Column 4 is computed excluding HS Chapters 1-29 (i.e., excluding agriculture, dairy, fishery and related sectors).

2. Labor Market Rigidity (Column 5) refers to the fraction of managers who report labor regulations as either a major business constraint or a severe business constraint in a World Bank Investment Climate Assessment survey conducted in 2002. This should be regarded as a de facto measure of labor market rigidity. 
Table 2: Labor Market Rigidity and Convergence Speed of CA/GDP (with Convergence Speed Estimated with Quarterly Data, Controlling for Seasonality)

\begin{tabular}{|c|c|c|c|c|c|c|c|}
\hline \multirow{3}{*}{\begin{tabular}{|l|} 
Labor market rigidity \\
\end{tabular}} & b1Q & $\mathrm{b} 1 \mathrm{Q}$ & $\mathrm{b} 1 \mathrm{Q}$ & $\mathrm{b} 1 \mathrm{Q}$ & b1Q & $\mathrm{b} 1 \mathrm{Q}$ & $\mathrm{b} 1 \mathrm{Q}$ \\
\hline & 1.063 & 1.174 & 1.16 & 1.214 & 1.192 & 1.108 & 1.077 \\
\hline & $(0.536)^{*}$ & $(0.615)^{*}$ & $(0.621)^{*}$ & $(0.562) *$ & $(0.566) *$ & $(0.575)^{*}$ & $(0.585)^{*}$ \\
\hline Exchange rate: crawling peg & & $\begin{array}{l}-0.173 \\
(0.20)\end{array}$ & $\begin{array}{l}-0.217 \\
(0.21)\end{array}$ & $\begin{array}{l}-0.173 \\
(0.19)\end{array}$ & $\begin{array}{l}-0.219 \\
(0.20)\end{array}$ & & \\
\hline Exchange rate: managed float & & $\begin{array}{l}-0.206 \\
(0.25)\end{array}$ & $\begin{array}{l}-0.212 \\
(0.25)\end{array}$ & & & & \\
\hline Exchange rate: float & & (dropped) & (dropped) & & & & \\
\hline Exchange rate: free falling & & $\begin{array}{l}-0.257 \\
(0.21)\end{array}$ & $\begin{array}{l}-0.239 \\
(0.21)\end{array}$ & & & & \\
\hline Exchange rate: dual market & & $\begin{array}{r}-0.182 \\
(0.41) \\
\end{array}$ & $\begin{array}{l}-0.177 \\
(0.41) \\
\end{array}$ & & & & \\
\hline $\begin{array}{l}\text { Exchange rate: managed float, float, free falling } \\
\text { or dual market }\end{array}$ & & & & $\begin{array}{l}-0.24 \\
(0.19)\end{array}$ & $\begin{array}{l}-0.229 \\
(0.19)\end{array}$ & & \\
\hline Exchange rate: float & & & & & & \begin{tabular}{|l|}
-0.184 \\
$(0.14)$ \\
\end{tabular} & $\begin{array}{l}-0.153 \\
(0.15) \\
\end{array}$ \\
\hline Exchange rate: intermediate & & & & & & \begin{tabular}{|l}
0.004 \\
$(0.18)$
\end{tabular} & $\begin{array}{l}0.041 \\
(0.20)\end{array}$ \\
\hline Log GDP / capita [10,000US\$] & & & $\begin{array}{l}0.109 \\
(0.14)\end{array}$ & & $\begin{array}{l}0.112 \\
(0.13)\end{array}$ & & $\begin{array}{l}0.071 \\
(0.13) \\
\end{array}$ \\
\hline Constant & $\begin{array}{c}-0.57 \\
(0.090)^{*}\end{array}$ & $\begin{array}{c}-0.405 \\
(0.179)^{*}\end{array}$ & $\begin{array}{c}-0.437 \\
(0.185)^{*}\end{array}$ & \begin{tabular}{|c|c|}
-0.408 \\
$(0.171)^{*}$
\end{tabular} & $\begin{array}{c}-0.441 \\
(0.177)^{*}\end{array}$ & $\begin{array}{l}-0.491 \\
(0.111)^{*}\end{array}$ & $\begin{array}{c}-0.54 \\
(0.144)^{*} \\
\end{array}$ \\
\hline $\begin{array}{l}\text { Observations } \\
\text { R-squared }\end{array}$ & $\begin{array}{c}30 \\
0.12\end{array}$ & $\begin{array}{c}30 \\
0.18\end{array}$ & $\begin{array}{l}30 \\
0.2\end{array}$ & $\begin{array}{c}30 \\
0.17\end{array}$ & $\begin{array}{l}30 \\
0.2\end{array}$ & $\begin{array}{l}30 \\
0.2\end{array}$ & $\begin{array}{c}30 \\
0.21\end{array}$ \\
\hline
\end{tabular}

Standard errors in parentheses, ${ }^{*}$ significant at $10 \%$

The dependent variable is a country-specific regression coefficient for an AR process with lags that characterizes the speed of convergence of the current account to its long run equilibrium

The exchange rate regime classifications used in columns 2-3 and 4-5 are based on Reinhart and Rogoff (2004). In columns 4-5, their last three classifications are combined. The exchange rate classifications in column 6-7 are based on Levy-Yeyati and Sturzenegger (2002) 
Table 3: Labor Market Rigidity and Convergence Speed of CA/GDP (with Convergence Speed Estimated with Annual Data)

\begin{tabular}{|c|c|c|c|c|c|c|c|}
\hline & b1A & $\mathrm{b} 1 \mathrm{~A}$ & b1A & b1A & b1A & $\mathrm{b} 1 \mathrm{~A}$ & b1A \\
\hline Labor market rigidity & \begin{tabular}{|c|}
1.012 \\
$(0.350)^{*}$ \\
\end{tabular} & \begin{tabular}{|c|}
1.228 \\
$(0.407)^{*}$
\end{tabular} & $\begin{array}{c}1.258 \\
(0.396)^{*}\end{array}$ & \begin{tabular}{|c|}
1.133 \\
$(0.381)^{*}$
\end{tabular} & $\begin{array}{c}1.151 \\
(0.371)^{*}\end{array}$ & $\begin{array}{c}0.969 \\
(0.383)^{*}\end{array}$ & $\begin{array}{c}1.031 \\
(0.367)^{*}\end{array}$ \\
\hline Exchange rate: crawling peg & & $\begin{array}{l}0.063 \\
(0.11)\end{array}$ & $\begin{array}{l}0.024 \\
(0.11)\end{array}$ & $\begin{array}{l}0.056 \\
(0.11)\end{array}$ & $\begin{array}{l}0.015 \\
(0.11)\end{array}$ & & \\
\hline Exchange rate: managed float & & $\begin{array}{l}-0.048 \\
(0.12)\end{array}$ & $\begin{array}{l}-0.036 \\
(0.12)\end{array}$ & & & & \\
\hline Exchange rate: float & & (dropped) & (dropped) & & & & \\
\hline Exchange rate: free falling & & $\begin{array}{l}-0.115 \\
(0.12) \\
\end{array}$ & $\begin{array}{l}-0.096 \\
(0.12) \\
\end{array}$ & & & & \\
\hline Exchange rate: dual market & & $\begin{array}{l}-0.235 \\
(0.29)\end{array}$ & $\begin{array}{l}-0.245 \\
(0.28)\end{array}$ & & & & \\
\hline $\begin{array}{l}\text { Exchange rate: managed float, float, } \\
\text { free falling or dual market }\end{array}$ & & & & $\begin{array}{l}-0.061 \\
(0.11)\end{array}$ & $\begin{array}{l}-0.037 \\
(0.11)\end{array}$ & & \\
\hline Exchange rate: float & & & & & & $\begin{array}{l}-0.028 \\
(0.08)\end{array}$ & $\begin{array}{l}-0.003 \\
(0.08)\end{array}$ \\
\hline Exchange rate: intermediate & & & & & & $\begin{array}{l}0.043 \\
(0.12)\end{array}$ & $\begin{array}{c}0.07 \\
(0.11)\end{array}$ \\
\hline Log GDP / capita [10,000US\$] & & & $\begin{array}{c}0.155 \\
(0.086)^{*}\end{array}$ & & $\begin{array}{c}0.162 \\
(0.086)^{*}\end{array}$ & & $\begin{array}{c}0.184 \\
(0.081)^{*}\end{array}$ \\
\hline Constant & \begin{tabular}{|c|}
-0.689 \\
$(0.059)^{*}$
\end{tabular} & $\begin{array}{c}-0.7 \\
(0.092)^{*}\end{array}$ & $\begin{array}{c}-0.747 \\
(0.093) *\end{array}$ & \begin{tabular}{|c|}
-0.692 \\
$(0.096)^{*}$
\end{tabular} & $\begin{array}{l}-0.745 \\
(0.097)^{*}\end{array}$ & $\begin{array}{c}-0.678 \\
(0.070)^{*}\end{array}$ & $\begin{array}{c}-0.76 \\
(0.076)^{*}\end{array}$ \\
\hline Observations & 49 & 47 & 47 & 47 & 47 & 47 & 47 \\
\hline R-squared & 0.15 & 0.21 & 0.27 & 0.18 & 0.25 & 0.16 & 0.25 \\
\hline
\end{tabular}

Standard errors in parentheses, * significant at $10 \%$

The dependent variable is a country-specific regression coefficient for an AR process with lags that characterizes the speed of convergence of the current account to its long run equilibrium

The exchange rate regime classifications used in columns 2-3 and 4-5 are based on Reinhart and Rogoff (2004). In columns 4-5, their last three classifications are combined. The exchange rate classifications in column 6-7 are based on Levy-Yeyati and Sturzenegger (2002) 
Table 4: Labor Market Rigidity and Current Account Convergence (with CA/GDP convergence speed estimated from a TAR model, quarterly data)

\begin{tabular}{|c|c|c|c|c|c|c|c|}
\hline & $\mathrm{b} 1 \mathrm{Q}$ & $\mathrm{b} 1 \mathrm{Q}$ & $\mathrm{b} 1 \mathrm{Q}$ & $\mathrm{b} 1 \mathrm{Q}$ & $\mathrm{b} 1 \mathrm{Q}$ & b1Q & $\mathrm{b} 1 \mathrm{Q}$ \\
\hline Labor market rigidity & $\begin{array}{c}0.93 \\
(0.464)^{*}\end{array}$ & $\begin{array}{c}1.008 \\
(0.527)^{*}\end{array}$ & $\begin{array}{c}0.987 \\
(0.518)^{*}\end{array}$ & $\begin{array}{c}1.038 \\
(0.485)^{*}\end{array}$ & $\begin{array}{c}1.004 \\
(0.474)^{*}\end{array}$ & $\begin{array}{c}1.04 \\
(0.512)^{*}\end{array}$ & $\begin{array}{c}0.989 \\
(0.514)^{*}\end{array}$ \\
\hline Exchange rate: crawling peg & & $\begin{array}{l}-0.183 \\
(0.17)\end{array}$ & $\begin{array}{l}-0.248 \\
(0.17)\end{array}$ & $\begin{array}{l}-0.183 \\
(0.16)\end{array}$ & $\begin{array}{r}-0.251 \\
(0.17)\end{array}$ & & \\
\hline Exchange rate: managed float & & $\begin{array}{l}-0.126 \\
(0.21)\end{array}$ & $\begin{array}{l}-0.136 \\
(0.21) \\
\end{array}$ & & & & \\
\hline Exchange rate: float & & (dropped) & (dropped) & & & & \\
\hline Exchange rate: free falling & & $\begin{array}{l}-0.248 \\
(0.18)\end{array}$ & $\begin{array}{l}-0.221 \\
(0.18)\end{array}$ & & & & \\
\hline Exchange rate: dual market & & $\begin{array}{l}-0.198 \\
(0.35)\end{array}$ & $\begin{array}{l}-0.191 \\
(0.34)\end{array}$ & & & & \\
\hline $\begin{array}{l}\text { Exchange rate: managed float, float, } \\
\text { free falling or dual market }\end{array}$ & & & & $\begin{array}{l}-0.212 \\
(0.16)\end{array}$ & $\begin{array}{l}-0.195 \\
(0.16) \\
\end{array}$ & & \\
\hline Exchange rate: float & & & & & & $\begin{array}{l}-0.109 \\
(0.12)\end{array}$ & $\begin{array}{l}-0.057 \\
(0.13) \\
\end{array}$ \\
\hline Exchange rate: intermediate & & & & & & $\begin{array}{l}-0.074 \\
(0.16)\end{array}$ & $\begin{array}{l}-0.012 \\
(0.17)\end{array}$ \\
\hline Log GDP / capita $[10,000 \mathrm{US} \$]$ & & & $\begin{array}{c}0.16 \\
(0.12)\end{array}$ & & $\begin{array}{l}0.169 \\
(0.11)\end{array}$ & & $\begin{array}{l}0.117 \\
(0.11)\end{array}$ \\
\hline Constant & $\begin{array}{c}-0.6 \\
(0.077)^{*}\end{array}$ & $\begin{array}{c}-0.439 \\
(0.153)^{*}\end{array}$ & $\begin{array}{c}-0.487 \\
(0.155)^{*}\end{array}$ & \begin{tabular}{|c|}
-0.441 \\
$(0.148)^{*}$
\end{tabular} & $\begin{array}{c}-0.491 \\
(0.148)^{*}\end{array}$ & $\begin{array}{c}-0.548 \\
(0.099)^{*}\end{array}$ & $\begin{array}{c}-0.629 \\
(0.126)^{*}\end{array}$ \\
\hline $\begin{array}{l}\text { Observations } \\
\text { R-squared }\end{array}$ & $\begin{array}{c}30 \\
0.13\end{array}$ & $\begin{array}{l}30 \\
0.2\end{array}$ & $\begin{array}{c}30 \\
0.26\end{array}$ & $\begin{array}{c}30 \\
0.18\end{array}$ & $\begin{array}{c}30 \\
0.25\end{array}$ & $\begin{array}{c}30 \\
0.15\end{array}$ & $\begin{array}{c}30 \\
0.19\end{array}$ \\
\hline
\end{tabular}

Standard errors in parentheses, * significant at $10 \%$

The dependent variable is a country-specific regression coefficient for a symmetric treshold AR process that characterizes the speed of convergence of the current account to its long run equilibrium

The exchange rate regime classifications used in columns 2-3 and 4-5 are based on Reinhart and Rogoff (2004). In columns 4-5, their last three classifications are combined. The exchange rate classifications in column 6-7 are based on Levy-Yeyati and Sturzenegger (2002) 
Table 5: Labor Market Rigidity and Current Account Convergence: (with CA/GDP convergence speed estimated with a TAR model, annual data)

\begin{tabular}{|c|c|c|c|c|c|c|c|}
\hline & b1A & $\mathrm{b} 1 \mathrm{~A}$ & $\mathrm{~b} 1 \mathrm{~A}$ & $\mathrm{~b} 1 \mathrm{~A}$ & $\mathrm{~b} 1 \mathrm{~A}$ & $\mathrm{~b} 1 \mathrm{~A}$ & $\mathrm{~b} 1 \mathrm{~A}$ \\
\hline Labor market rigidity & $\begin{array}{c}0.96 \\
(0.505)^{*}\end{array}$ & $\begin{array}{c}0.99 \\
(0.565)^{*}\end{array}$ & $\begin{array}{c}1.049 \\
(0.548)^{*}\end{array}$ & $\begin{array}{c}1.162 \\
(0.554)^{*}\end{array}$ & $\begin{array}{c}1.204 \\
(0.534)^{*}\end{array}$ & $\begin{array}{c}0.937 \\
(0.590)\end{array}$ & $\begin{array}{c}1.052 \\
(0.556)^{*}\end{array}$ \\
\hline Exchange rate: crawling peg & & $\begin{array}{l}0.063 \\
(0.16)\end{array}$ & $\begin{array}{l}0.032 \\
(0.16)\end{array}$ & $\begin{array}{l}0.041 \\
(0.18)\end{array}$ & $\begin{array}{l}-0.004 \\
(0.17)\end{array}$ & & \\
\hline Exchange rate: managed float & & $\begin{array}{l}0.013 \\
(0.18)\end{array}$ & $\begin{array}{c}0.05 \\
(0.18)\end{array}$ & & & & \\
\hline Exchange rate: float & & $\begin{array}{c}-0.698 \\
(0.354)^{*}\end{array}$ & $\begin{array}{c}-0.628 \\
(0.345)^{*}\end{array}$ & & & & \\
\hline Exchange rate: free falling & & $\begin{array}{l}-0.246 \\
(0.18)\end{array}$ & $\begin{array}{l}-0.189 \\
(0.18) \\
\end{array}$ & & & & \\
\hline Exchange rate: dual market & & $\begin{array}{l}-0.162 \\
(0.38)\end{array}$ & $\begin{array}{l}-0.16 \\
(0.37)\end{array}$ & & & & \\
\hline $\begin{array}{l}\text { Exchange rate: managed float, float, } \\
\text { free falling or dual market }\end{array}$ & & & & $\begin{array}{l}-0.134 \\
(0.17)\end{array}$ & $\begin{array}{l}-0.078 \\
(0.16)\end{array}$ & & \\
\hline Exchange rate: float & & & & & & $\begin{array}{l}-0.068 \\
(0.12)\end{array}$ & $\begin{array}{l}-0.048 \\
(0.12)\end{array}$ \\
\hline Exchange rate: intermediate & & & & & & $\begin{array}{l}0.033 \\
(0.18)\end{array}$ & $\begin{array}{l}0.053 \\
(0.17)\end{array}$ \\
\hline Log GDP / capita [10,000US\$] & & & $\begin{array}{c}0.283 \\
(0.161)^{*}\end{array}$ & & $\begin{array}{c}0.328 \\
(0.170)^{*}\end{array}$ & & $\begin{array}{c}0.365 \\
(0.157)^{*}\end{array}$ \\
\hline Constant & $\begin{array}{c}-0.794 \\
(0.085)^{*}\end{array}$ & $\begin{array}{c}-0.758 \\
(0.139)^{*}\end{array}$ & $\begin{array}{c}-0.865 \\
(0.148)^{*}\end{array}$ & $\begin{array}{c}-0.77 \\
(0.146)^{*}\end{array}$ & $\begin{array}{c}-0.892 \\
(0.154)^{*}\end{array}$ & $\begin{array}{c}-0.776 \\
(0.105)^{*}\end{array}$ & $\begin{array}{c}-0.915 \\
(0.116)^{*}\end{array}$ \\
\hline $\begin{array}{l}\text { Observations } \\
\text { R-squared }\end{array}$ & $\begin{array}{c}42 \\
0.08\end{array}$ & $\begin{array}{c}39 \\
0.29\end{array}$ & $\begin{array}{c}39 \\
0.35\end{array}$ & $\begin{array}{c}39 \\
0.14\end{array}$ & $\begin{array}{c}39 \\
0.22\end{array}$ & $\begin{array}{l}39 \\
0.1\end{array}$ & $\begin{array}{c}39 \\
0.22\end{array}$ \\
\hline
\end{tabular}

Standard errors in parentheses, * significant at $10 \%$

The dependent variable is a country-specific regression coefficient for a symmetric treshold AR process that characterizes the speed of convergence of the current account to its long run equilibrium

The exchange rate regime classifications used in columns 2-3 and 4-5 are based on Reinhart and Rogoff (2004). In columns 4-5, their last three classifications are combined. The exchange rate classifications in column 6-7 are based on Levy-Yeyati and Sturzenegger (2002) 
Table 6: Labor Rigidity and Standard Deviation of (CA/Total Trade)

\begin{tabular}{|c|c|c|c|c|c|c|c|c|}
\hline \multirow{3}{*}{ Labor market rigidity } & all obs & all obs & all obs & all obs & \multicolumn{4}{|c|}{ excl. BRA \& NIC excl. BRA \& NIC excl. BRA \& NIC excl. BRA \& NIC } \\
\hline & 13.712 & 15.745 & 12.176 & 12.509 & 14.518 & 15.151 & 12.93 & 13.39 \\
\hline & $(6.511)^{*}$ & $(7.403)^{*}$ & $(6.565)^{*}$ & $(6.795)^{*}$ & $(6.215)^{*}$ & $(7.170)^{*}$ & $(6.421)^{*}$ & $(6.312)^{*}$ \\
\hline \multirow[t]{2}{*}{ Exchange rate: crawling peg } & & 6.433 & 7.068 & & & 8.015 & 7.478 & \\
\hline & & $(9.83)$ & $(10.01)$ & & & $(9.29)$ & $(9.51)$ & \\
\hline \multirow[t]{2}{*}{ Exchange rate: managed float } & & 6.111 & & & & 6.691 & & \\
\hline & & $(10.98)$ & & & & $(10.48)$ & & \\
\hline \multirow[t]{2}{*}{ Exchange rate: float } & & 31.874 & & & & 28.188 & & \\
\hline & & $(17.144)^{*}$ & & & & $(16.090)^{*}$ & & \\
\hline \multirow[t]{2}{*}{ Exchange rate: free falling } & & 14.226 & & & & 5.148 & & \\
\hline & & $(16.35)$ & & & & $(15.92)$ & & \\
\hline \multirow[t]{2}{*}{ Exchange rate: dual market } & & -0.282 & & & & 2.106 & & \\
\hline & & $(23.12)$ & & & & $(21.66)$ & & \\
\hline \multirow{2}{*}{$\begin{array}{l}\text { Exchange rate: managed float, float, } \\
\text { free falling or dual market }\end{array}$} & & & 14.701 & & & & 8.405 & \\
\hline & & & $(10.10)$ & & & & $(10.16)$ & \\
\hline \multirow[t]{2}{*}{ Exchange rate: float } & & & & 1.746 & & & & -0.668 \\
\hline & & & & $(7.56)$ & & & & $(6.92)$ \\
\hline \multirow[t]{2}{*}{ Exchange rate: intermediate } & & & & 1.653 & & & & 13.815 \\
\hline & & & & $(11.54)$ & & & & $(11.48)$ \\
\hline \multirow[t]{2}{*}{$\operatorname{sd}(\ln C P I)$} & 9.551 & 9.944 & 9.475 & 9.665 & -4.038 & -3.484 & -3.271 & -6.571 \\
\hline & $(1.943)^{*}$ & $(2.083)^{*}$ & $(1.934)^{*}$ & $(2.097)^{*}$ & $(5.18)$ & $(5.68)$ & $(5.50)$ & $(5.69)$ \\
\hline \multirow[t]{2}{*}{$\operatorname{sd}(\operatorname{lnGDP}) /$ mean $(\operatorname{lnGDP})$} & -125.662 & -181.012 & -168.784 & -125.979 & 218.668 & 222.032 & 178.874 & 289.532 \\
\hline & $(84.62)$ & $(134.70)$ & $(91.116)^{*}$ & $(91.36)$ & $(143.98)$ & $(201.53)$ & $(169.61)$ & $(158.596)^{*}$ \\
\hline \multirow[t]{2}{*}{ Constant } & 44.657 & 38.278 & 37.781 & 43.566 & 40.204 & 32.043 & 35.26 & 38.064 \\
\hline & $(6.065)^{*}$ & $(8.855)^{*}$ & $(8.623)^{*}$ & $(6.792)^{*}$ & $(6.377)^{*}$ & $(8.898)^{*}$ & $(8.464)^{*}$ & $(6.901)^{*}$ \\
\hline Observations & 42 & 41 & 41 & 41 & 40 & 39 & 39 & 39 \\
\hline R-squared & 0.46 & 0.53 & 0.5 & 0.47 & 0.19 & 0.26 & 0.2 & 0.22 \\
\hline
\end{tabular}

Standard errors in parentheses, * significant at $10 \%$

The dependent variable is the country-specific standard deviation of Current Account / trade for the period from 1980 to 2005 (or all years for which data is available within this period)

The exchange rate regime classifications used in columns 2-3 and 6-7 are based on Reinhart and Rogoff (2004). In columns 3 and 7, their last three classifications are combined. The exchange rate classifications in column 4 and 8 are based on Levy-Yeyati and Sturzenegger (2002)

$\mathrm{sd}(\operatorname{lnCPI})$ is the standard deviation of the natural $\log$ of the Consumer Price Index and sd(lnGDP)/mean(lnGDP) is the standard deviation of the natural log of GDP divided by the mean of the natural log of GDP for each country over the period from 1980 to 2005. 
Table 7: List of countries in regressions

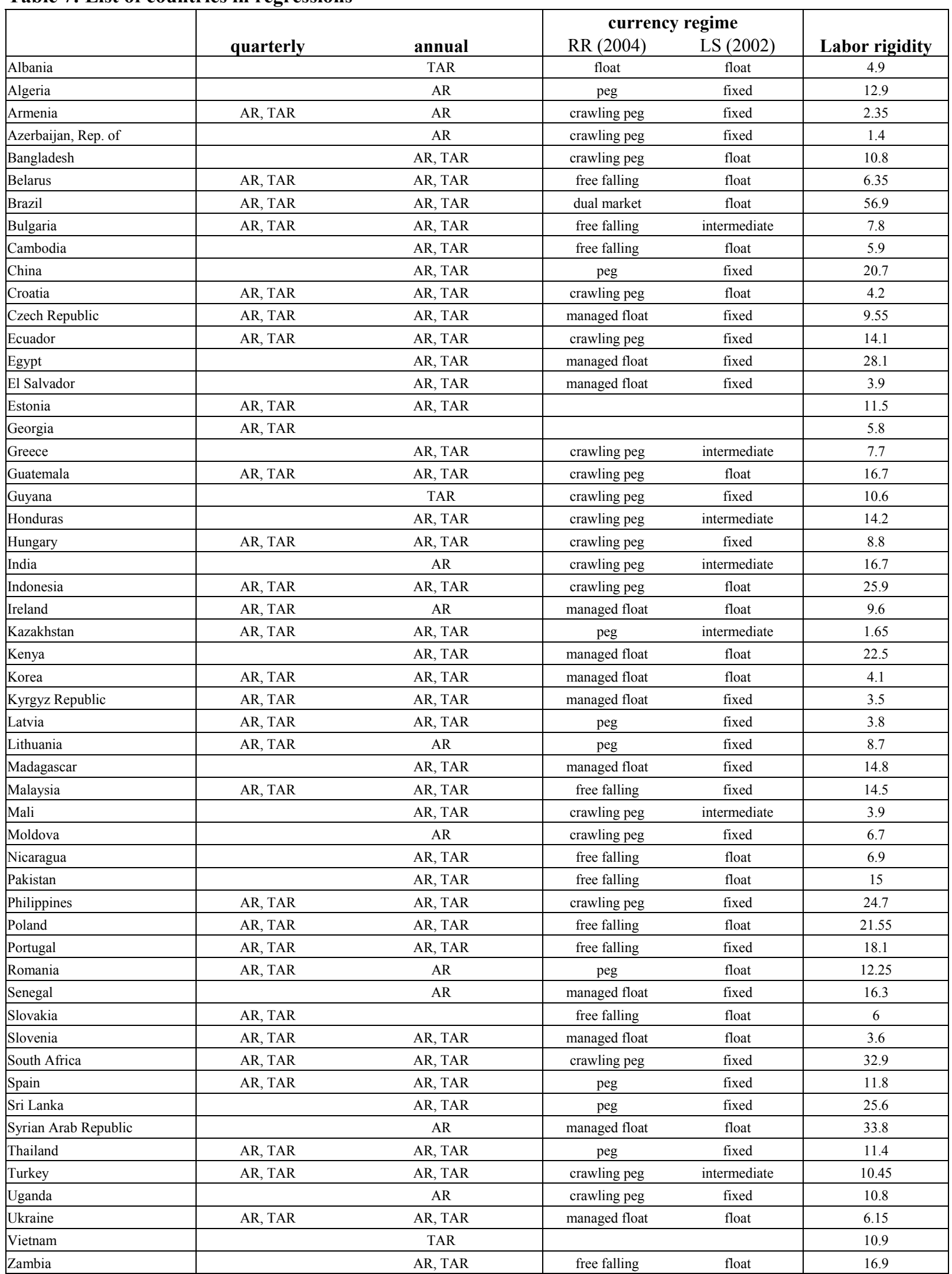

AR and TAR indicate data availability for the regressions based on autoregressive process (AR) and threshold autoregressive process (TAR) Current Account convergence coefficients.

Currency regime reports the classification a country receives in Reinhart-Rogoff (RR 2004) and Yeyati-Sturzenegger (YS 2002) during most of the years between 1980 and 2005 for which their data is available. If two different classifications have been maintained for the same number of years, the more recent one is chosen.

Labor rigidity reports the share of managers ranking labor regulations as a major business constraint in a World Bank Enterprise Survey. 
Table 8: Description of exchange rate regime classifications in Reinahrt and Rogoff (2004):

\begin{tabular}{|rl|}
\hline peg (excluded) & $\begin{array}{l}\text { No separate legal tender } \\
\text { Pre announced peg or currency board arrangement } \\
\text { Pre announced horizontal band that is narrower than or equal to }+/-2 \% \\
\text { De facto peg }\end{array}$ \\
\hline \multirow{2}{*}{ crawling peg } & $\begin{array}{l}\text { Pre announced crawling peg } \\
\text { Pre announced crawling band that is narrower than or equal to }+/-2 \% \\
\text { De factor crawling peg } \\
\text { De facto crawling band that is narrower than or equal to }+/-2 \%\end{array}$ \\
\hline & $\begin{array}{l}\text { Pre announced crawling band that is wider than or equal to }+/-2 \% \\
\text { De facto crawling band that is narrower than or equal to }+/-5 \% \\
\text { managed float }\end{array}$ \\
& Moving band that is narrower than or equal to $+/-2 \%$ \\
& Managed floating \\
\hline float & Freely floating \\
\hline free falling & Freely falling \\
\hline dual market & Dual market in which parallel market data is missing. \\
\hline
\end{tabular}

Reference: Reinhart, C. and K. Rogoff (2004): The modern history of exchange rate arrangements: A reinterpretation. NBER Working Paper 8963. http://www.nber.org/papers/w8963

\begin{tabular}{|l|}
\hline Levy-Yeyati and Sturzenegger (2002): \\
\hline floating \\
\hline intermediate \\
\hline fixed (excluded) \\
\hline
\end{tabular}

Reference: Levy-Yeyati, E. and Frederico Sturzenegger (2002): A de facto classification of exchange rate regimes. http://200.32.4.58/ ely/AppendixAER.pdf 